\title{
Narrative Communication Strategies: Best Practices for NGOs Seeking Funding from CIDA
}

\author{
By Abigail Gamble \\ Student Number: \\ Supervisor: Dr. Catherine Schryer \\ The Major Research Paper is submitted \\ in partial fulfillment of the requirements for the degree of \\ Master of Professional Communication \\ Ryerson University \\ Toronto, Ontario, Canada
}

September 15, 2011 


\begin{abstract}
Author's Declaration Page
I hereby declare that I am the sole author of this Major Research Paper.

I authorize Ryerson University to lend this MRP to other institutions or individuals for the purpose of scholarly research.
\end{abstract}

Signature

I further authorize Ryerson University to reproduce this MRP by photocopying or by other means, in total or in part, at the request of other institutions or individuals for the purpose of scholarly research.

Signature 


\section{Acknowledgements}

This Major Research Paper could not have been successfully completed without the thorough guidance of my graduate supervisor, Dr. Catherine Schryer. Many thanks are due for her patience and insight. She not only provided me with constructive editing feedback throughout the process of writing this paper, but also leant, without fail, her invaluable expertise and perspective on producing a research paper in the field of Professional Communication.

I am grateful to all the faculty and staff at the School of Professional Communication who I have had the pleasure of learning from and working with, but must highlight my especial appreciation for Dr. Wendy Freeman and Dr. Joanne DiNova. Working with both of them as a Graduate Assistant was one of the highlights of my graduate school experience. Thank you for providing me with so many opportunities to learn and explore the academic world. I also must thank Dr. DiNova for acting as my second reader and providing me with a valuable perspective on the final draft of my MRP.

Finally, I wish to express my gratitude to my fellow classmates in the Master of Professional Communication program for their friendship and support. 


\section{Dedication}

I would not have been a student in the MPC program, let alone the author of this paper without the unwavering support and love of my family - my amazing parents, Greg and Chantha Gamble and my siblings, Melody, Nathan and Samuel Gamble. This MRP is dedicated to you. I would also like to dedicate it to my aunts, Gillian Gamble and Dorothy Norng, for your endless encouragement throughout my schooling. As well, this paper is dedicated to David Bailey for your constant and patient support during most of my academic life.

Finally, I would like to dedicate this MRP to my friends and fellow students in the Master of Professional Communication program, Sarah Stockdale, Sara Rosenfeld, Adam Ferraro and Kenneth Davie. Your camaraderie during the many days and nights of researching, brainstorming, writing and editing was a wonderfully enriching and unforgettable part of my graduate school experience.

Thank you all. 


\section{Table of Contents}

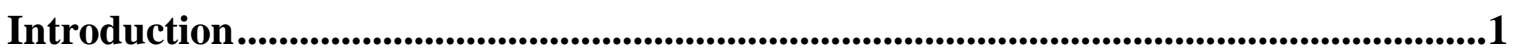

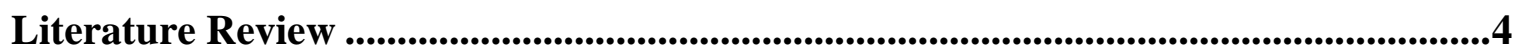

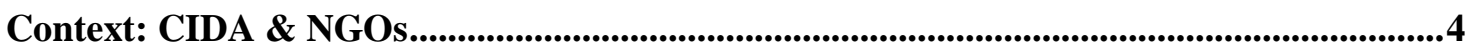

Communication Strategies ........................................................................................................

Theoretical Framework......................................................................................................13

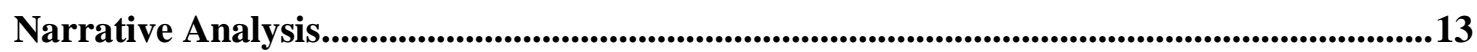

The Proposal Narrative ...........................................................................................................................15

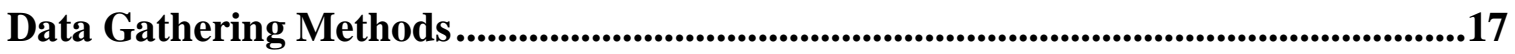

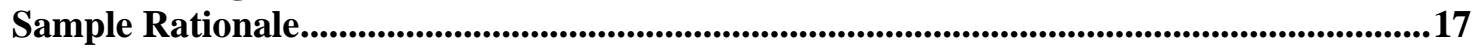

Methods for Analysis .........................................................................................................................19

Methods for Discussing Analysis ..........................................................................................................20

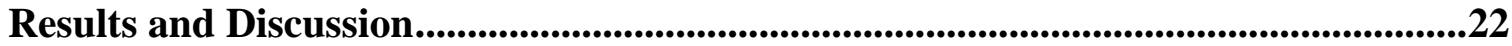

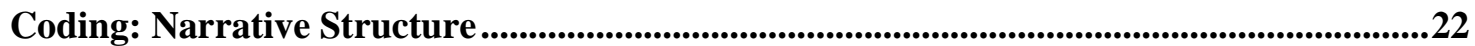

Coding: Linguistic Structure of Narratives .........................................................................26

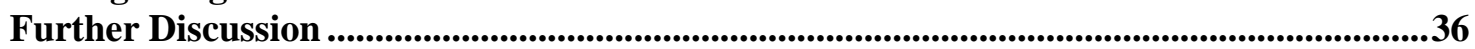

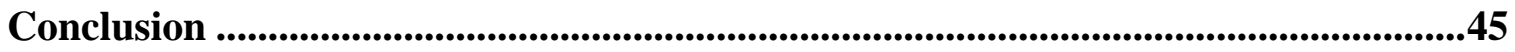

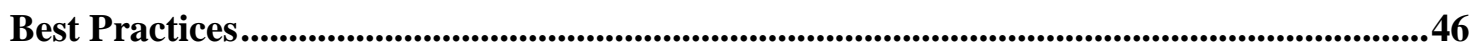

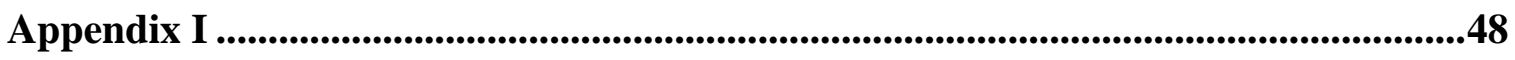

Appendix II ......................................................................................................................55

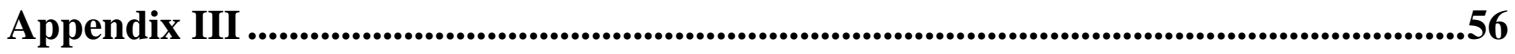

References ...............................................................................................................662 
Narrative Communication Strategies

In June 2010, at the G-8 Muskoka Initiative on Maternal, Newborn and Child Health, Prime Minister Stephen Harper promised that Canada would provide 2.85 billion dollars (over five years) in funding to support health initiatives for mothers and children in developing countries (Government of Canada, 2011). This focus on maternal and child health is in keeping with three of the eight Millennium Development Goals, which focus on empowering women, reducing child mortality and improving maternal health.

All United Nation member states have agreed to support these goals and achieve specified health, gender, environmental and educational targets by 2015 (World Health Organization [WHO], 2011). Canada's government has thus committed tremendous resources, both financial and administrative, to achieve these targets that relate to maternal and child health. Seventy-five million dollars of this promised money is being disseminated by CIDA (Canadian International Development Agency) to Canadian NGOs (Non-governmental organizations) who can provide program proposals that focus on maternal, newborn and child health initiatives in third world countries - most of the countries eligible for the funding are located in Africa (CIDA, 2010).

It is from interest in the Muskoka initiative and the CIDA funding specifically that this research project developed. When considering the relationship between NGOs and government as in this situation - and specifically in this case a Canadian NGO and the Canadian government - a few key questions arose. When producing proposals for government, specifically CIDA, what strategies do NGOs employ when communicating those proposals in the hopes that they will be allocated funds? How can these communication strategies be analyzed?

Though of course there are many methods by which the latter question can be 
Narrative Communication Strategies

answered, the one chosen for this project is the study of narrative. By using discourse analysis to analyze narratives embedded within proposals for funding produced by a Canadian NGO it is my goal to reveal communication strategies that are successful or unsuccessful when approaching government agencies for not-for-profit funding. Further understanding of such strategies can potentially provide NGOs with an idea of best practices in regards to communication proposal strategies. Thus the research question being asked is:

What communication strategies - analyzed as narratives on the topic of maternal, newborn and child health - used by non-governmental aid organizations are most successful when submitting funding proposals to the Canadian International Development Agency?

The NGO that will serve as the case study for exploring this research question is the African Medical Research Foundation (AMREF) Canada. Located in downtown Toronto, AMREF Canada is the Canadian branch of AMREF International, an NGO that specifically focuses on health development in Africa. The Canadian branch of the organization is mainly involved in awareness and fundraising initiatives in Toronto, Ottawa and Calgary. The money raised by AMREF Canada helps support programs throughout Africa but is specifically focused on Ethiopia, Kenya, South Africa, Southern Sudan, Tanzania and Uganda. Programs range from training for health care professionals to clean water and sanitation initiatives in needy communities (AMREF, 2011). The current ten year strategy for the organization is "finding ways to link health services to the people that need them most by focusing more on people, and less on diseases making responses tailor-made to specific community needs regardless of religion, race, 
Narrative Communication Strategies

ethnicity or gender" (AMREF, 2011).

The previously outlined research question will be explored in this Major Research Paper by first considering scholarly literature that relates to the topic of NGOs and government, narrative analysis and funding proposals by NGOs to government agencies (CIDA specifically when possible). To begin, the context will be established for understanding the issues at play for Canadian NGOs when interacting with CIDA, and a discussion of the relevance of the research question to the current literature will be explored. Next the literature review will consider perspectives for studying communication strategies for funding. This will then lead to a discussion of the theoretical framework based on narrative analysis and employing discourse analysis methods that will be utilized to analyze a specific proposal from AMREF Canada. Once the methods that were used for analysis have been clearly established, the findings of the research will be presented and interpreted through the lens of the framework previously discussed. 
Narrative Communication Strategies

\section{Literature Review}

\section{Context: CIDA \& NGOs}

Before delving into an analysis of narratives found in proposals for funding it is necessary to understand the context in which Canadians NGOs are situated (in relation to CIDA), in order to understand what issues necessitate the topic explored in this paper.

For the past five decades CIDA has played a central role in the policy and administration of Official Development Assistance (ODA) on behalf of Canada to countries in need internationally. Founded in 1968, the organization is responsible for the operation of "bi-lateral, voluntary, business, food, and international humanitarian aid channels" (Morrison, 1998, p. 6) and functions as a branch of the Canadian government. Their budget as of 1998 operated and disseminated three-quarters of the ODA produced by Canada. Soon after their creation (in the early 1970s), CIDA began funding external development programs including those administered by international NGOs (INGOs) (Morrison, 1998). The relationship between such NGOs and CIDA is the topic of focus for this paper.

When discussing the definition of INGOs in their book on development issues between Canada and the third world, Swift and Tomlinson (1991) point out that any discussion about this type of organization must consider the fact that their identity is rooted in what they are not - namely, government. Because "NGOs support or implement programs for which governments are normally thought to be responsible; and they often do these things in co-operation with governments, relying to a large degree on government funds," (Swift \& Tomlinson, 1991, p. 163) it is necessary to highlight that they are still separate institutions with their own mandates, which can be different than 
Narrative Communication Strategies

those of the government from whom they derive their funding. This is an important perspective to consider when contemplating the research question for this paper. When seeking funding for programs they have produced as an extension of their own unique mandate, NGOs may not necessarily be aligned with the mandate of the agency they are seeking funding from. A natural question that then arises is: is it necessary for organizations to alter or adjust the development of their aid programs (as outlined in their funding proposals) in order to receive funding from government?

Previous literature on the subject seems to imply that this is indeed necessary because of the power structure at play between NGOs and agencies like CIDA. Swift and Tomlinson (1991) write that questions regarding whose interests (in terms of mandate, relevance and independence) are served have shaped the evolution of INGOs in the past decades. In the 1970s and 1980s an evolving political and social awareness of the needs of third world nations led to the development of INGOs who were either homegrown institutions or branches of larger, worldwide organizations (many of whom originated in the United States) like AMREF Canada. By the 1980s some larger organizations were getting anywhere from 75 to 90 per cent of their funding from CIDA (though smaller INGOs, in an attempt to maintain their autonomy, received far less of their funding from government and instead gathered donations from private sources). Almost $60 \%$ of this funding was utilized for development assistance projects, which is by definition what the Muskoka Initiative funding is (Swift \& Tomlinson, 1991).

Swift and Tomlinson (1991) theorize that this funding pattern both seriously affected the question of independence and relevance of the organizations that received such high amounts of their total revenue from government. In terms of independence the 
Narrative Communication Strategies

question arose as to whether these NGOs were actually autonomous institutions or simply just arms of the Canadian government. Relevance is an even stickier subject, the question being: who are INGOs responsible to in terms of political interest and who guides their vision - the agencies from which they receive their funding or the local partners (including national governments) in developing countries that they work with to create development assistance projects (Swift \& Tomlinson, 1991)? These are two key questions (and areas of interest - independence and relevance) that were considered when doing discourse analysis of the funding proposal developed by AMREF.

A final key question regarding the relationship between NGOs and CIDA relates back to the idea of the power relation between the two institutional types. In his appraisal of CIDA policies, Pratt (1994) examines exactly what definition can be used to describe the relationship between the two. "The CIDA discourse routinely (and revealingly) talks of 'using' partners to accomplish one or another of CIDAs objectives [again, the idea of different mandates arises]," (Pratt, 1994, p. 113) but really, he argues, the use of the word "partner" is a misnomer. Use of the word partnership assumes equal agreement and responsibility for goals and methods of achieving those goals; however within the current structure, there is little room for NGOs to either criticize or suggest their own ideas for policy creation. Power is not shared and thus the relationship is more that of allies than partners, Pratt suggests (Pratt, 1994).

These three key points - considering independence, relevance and (broadly) the power relations between NGOs and CIDA-- both shape some of the questions that were considered when doing discourse analysis as well as set the context for the relevance of the research question. The nuances that affect the relationship between NGOs and CIDA 
Narrative Communication Strategies

arguably infer that a systematic, strategic approach to both offering (on the part of CIDA) and seeking (on the part of NGOs) funding is an integral part of the overall process. Understanding best practices would thus likely occur by analyzing the strategies evident with funding proposals using these three broad concepts. The next section, which considers literature regarding communication strategies that have previously been used by NGOs/non-profits when seeking funding from government, also relates back to these key points.

\section{Communication Strategies}

In order to determine best practices in regards to strategies utilized by NGOs and the strategies government agencies expect to be used, it is helpful to consider the different strategic perspectives that each kind of organization might regularly utilize when dealing with the other. This section will consider categories for organization of both NGOs strategies and government strategies.

The communication strategies (embedded within narratives) that are utilized by an NGO when developing a funding proposal are an extension of their strategy as an organization. Musambira (1997) in his classification of NGOs active in East Africa where AMREF provides most of their development assistance programming (AMREF, 2011) - developed 5 categories for grouping these types of organization. His categories can be used to situate AMREF Canada in relation to other NGOs and to understand its basic strategic perspective in regards to development.

Musambira (1997) reviewed previous literature on NGO typologies and merged two of the most common to develop his five strategic categories for organizing development NGOs. The first, Relief and Welfare, views problems in third world 
Narrative Communication Strategies

countries as "emergency deficiencies or shortages" (Musambira, 1997, p. 24) which implies strategies for a solution to be providing emergency care and products that support the basic necessities of life.

The second, Economic and Social Community Development, is the kind of NGO that is focused not just on providing aid in the short term, but in the creation of projects which locals can maintain themselves, at least on a small scale, implying strategies that focus on education and training rather than simply emergency care (Musambira, 1997).

The third strategic category is Political Community Development and is similar to the previous category but goes a step further. While advocating for communities to be self-reliant in terms of basic human needs such as health and food production, these kinds of organizations are also focused on politically empowering the disenfranchised.

Development strategies that might emerge from NGOs in this category would be a focus on human rights and the development of citizen groups (Musambira, 1997).

The fourth category, Sustainable Systems Development, does not focus on basic human needs but rather is completely concentrated on systemic institutional/policy issues that lead to situations where communities suffer from social, economic and political problems. The strategy employed here is to work at many levels to bring about policy changes - so self-reliance on the part of local communities is encouraged but so is development that aims to re-design a flawed system that is in place (Musambira, 1997).

Finally, the fifth category, The Peoples Movements Strategy, is similar to but even broader in scale than the Sustainable Systems Development category - in this case the belief is that system change should occur not just at the local and national level, but at a global level as well. The strategy used then is mobilizing people based on a shared belief 
Narrative Communication Strategies

or idea (Musambira, 1997). Musambira (1997) hastens to point out that NGOs are often characterized as existing in more than one of the five categories.

When applying the five categories to the context of AMREF as an organization there are two categories that stand out: the second and the fifth. AMREF's mandate as outlined in their strategy is to focus on people and communities, serving those in dire need but also "improving access to health treatment and preventing poor health through community education," (AMREF, 2011) thus placing them in the category of economic and social community development. Their goal as an organization is to provide more than basic care - it is to provide communities with the means to proactively care for their own health needs by attaining health education and training (AMREF, 2011). Arguably, though, the organization could also be said to fit into the fifth category, Peoples Movements Strategies, which advocates for more high level, global mobilization of people and resources. Both the fact of them being members of a larger, international aid organization and their stated dedication to helping achieve Millennium Development Goals, focusing on maternal, newborn and child health issues in research and in partnerships with other organizations such as UNICEF place them in this category (AMREF, 2011).

AMREF is not alone in its focus on both economic and social community development; the most common type of NGO Musambira found in his analysis were placed into this category, with 40 per cent of organizations analyzed fitting the description. The basic tenet of the overall strategic concept employed by AMREF when producing development programs, if using Musambira's (1997) system of organization, is that "development is facilitated by unlocking the potential of local people through 
Narrative Communication Strategies

education or training in various skills and ensuring that they're basic human needs are fulfilled" (p. 25).

To return to the previously discussed variables though, considering independence, relevance and power relations the question is, does CIDA support (and even encourage) this strategy in the funding proposals they receive? Is this the overarching organizational strategy they are looking for? Though AMREF might be acting as an autonomous entity (independent), seeking to provide development programs that partner with local communities (who they have chosen to be responsible to and from whom they gain relevance) are they able to create, at the least, an "allied" relationship with CIDA in terms of how Pratt (1994) would define it? One way of determining this is to consider a framework that outlines and categorizes best practices for successful relationships between NGOs and government in a Canadian context.

Through empirical analysis of 22 non-profit organizations in Manitoba, Brown and Troutt (2004) found case studies of successful non-profit/government relationships by comparing funding relationships and organizational stress in relation to funding (such as budgeting, insecurity about the relationship with government etc.). Their findings were that those organizations with the best, most successful relationships with government had very specific kinds of funding arrangements with them. These funding arrangements developed because of the use of structural and attitudinal communication strategies, which encouraged and created a cooperative relationship. Brown and Troutt (2004) write that this cooperative relationship occurs when:

(a) the delineation of decision making between government and organizations reflects the use of organizational [the NGO] expertise, (b) the program officers 


\section{Narrative Communication Strategies}

demonstrate a knowledge of the sector and skill at promoting effectiveness and efficiency, and (c) the contracts minimize the uncertainty and ambiguity that contribute to high transaction costs. (p. 11)

Interestingly, though this framework for relationship seems to leave more room for NGOs to maintain their own independent mandate and choice of relevance in terms of at least having their expertise tapped into (if not having a say in policy). The result, according to the authors, was successful implementation of the policy goals of government. Though it has been made clear that power in the relationship between NGOs and government is skewed in favor of the government agency, best results emerge when government utilize the expertise and work, to some degree, with the mandate of their "allies."

In a second source looking at the development of relationships between government and non-profit organizations, Ramanath and Ebrahim (2010) found that strategies for successful interaction with government in another set of case studies (looking at prominent NGOs working in the slums and squatter houses in Mumbai) were also determined by the government in question.

The authors drew on numerous typologies in order to develop their categories of successful strategies used, but developed two key concepts. The first is the assumption that an organization's relationship with government is either in opposition to the government, in subjugation to them or in collaboration with them depending on the political space and climate of the country in question. The second is that the strategy utilized (depending on the relationship with government that has already been ascertained by the previous concept) is either "proactive, reactive or somewhere in between" 
Narrative Communication Strategies

(Ramanath \& Ebrahim, 2010).

The strategies that Ramanath and Ebrahim (2010) focus on in their case study are not applicable to the topic at hand as they relate to the specific situation they were analyzing. However, their overall framework for analyzing strategy is of benefit to the analysis of AMREF's proposal for funding. They argue that the strategies employed by NGOs when approaching government relate to what they term as the "Theory of Change" held by an organization. This is the logic of intervention or the overarching perspective of the NGO on how to achieve successful change: "a framing of the root problem to be addressed and the pathway or steps [strategy] required to ameliorate that problem" (Ramanath \& Ebrahim, 2010, p. 33). This Theory of Change then dictates what the strategic aims of the organization are and how they go about achieving those strategic aims, essentially, tactics. The authors note that generally there is both a primary strategic tactic employed by NGOs as well as sub-strategic tactics (Ramanath \& Ebrahim, 2010).

Having placed our case study, AMREF Canada in a strategic category and outlined frameworks for communication strategies that were successful for the building of relationships between other NGOs and government, it is time to determine what the nature of the relationship between the organization and CIDA actually is: proactive, reactive or somewhere in between as well as the specific nuances of that relationship. Analysis of the communication strategies, and specific tactics, employed by AMREF Canada in their funding proposal will reveal the kind of relationship with CIDA they present and imply in their proposal. This will be the marker for measuring whether the strategies used were successful and will lead to a discussion of best practices. 
Narrative Communication Strategies

\section{Theoretical Framework}

\section{Narrative Analysis}

Narrative analysis was chosen as the overarching framework for this paper and discourse analysis methods as the tool of analysis. Narrative in a theoretical sense is broadly defined as "articulated language, whether oral or written, pictures, still or moving, gestures and an ordered mixture of all those substances...[it] is present in myth, legend, fables, tales, short stories, epics, history, tragedy, drame [suspense drama], comedy, pantomime, paintings, stained glass windows, movies, local news, conversation" (Barthes, 1975, p. 237). Essentially, at a very basic social level, we as human beings communicate by telling stories. The reason narrative analysis was chosen as the theoretical framework for this study is because narrative speaks to that basic communicative imperative. Furthermore, narrative analysis often utilizes patterns of linguistic analysis that serve as a broad, sense-making tool when studying discourse between people/groups (Johnstone, 2004).

The specific narrative framework used to analyze the AMREF Canada proposal is Structural Analysis of Narrative as outlined by Barthes. Barthes (1975) uses a very linear pattern of analysis to break down how discourse can be analyzed using narrative. Discourse, he writes, is organized as a function of linguistics that can be broken down into units and rules like a sentence. Also like a sentence, discourse has its own grammar, which if deciphered (in the same way sentences are, linguistically) can reveal the levels of meaning found within any narrative (Barthes, 1975).

Barthes breaks down narrative work into three levels of meaning, that of function, action and narration. Function (measured in units) is the "soul" or element within a 


\section{Narrative Communication Strategies}

narrative that is brought to fruition throughout the story (Barthes, 1975). Essentially it is the essence of the plot. He further breaks down function into two units for measurement: the first distributional, the second integrative. Distributional refers to units that infer "complementary and consequential acts" - so they follow a very basic narrative pattern where one concept or idea leads to a following concept or idea. An example would be, "Sally baked a cake. Sally then ate the cake." Integrative, however, is more nuanced and refers to units within narrative that inform character building and setting, for instance, setting up the atmosphere of a scene or inferring a character's identity (Barthes, 1975).

Action, simply put, refers to the structural status of characters in relation to other characters, which can be one of three main spheres of action. Barthes (1975) clarifies that characters are described based on what they do as oppose to how they are described (or any other classification). The first type of action, communication, is the basic subjectobject relationship in discourse, which is attributive and circumstantial. This would be any action in which a character (the subject) is communicating with or to another character or object simply for the purpose of communicating, say, "Fred is eating the apple". The second sphere of action, desire, is based on a giver-receiver model of discourse where one (or more) characters wishes to get or give to another character or object (Barthes, 1975). For example, "Fred cut a piece of the apple and gave it to Sally." This sphere is very much related to the study of power relation within narrative. Finally the third sphere is ordeal, where the relationship is a struggle between adjutant and opposer (Barthes, 1975). A simple example would be "Fred hesitated about giving a piece of his apple to Sally who he did not like, but who was hungry."

The third, deepest level of meaning to be derived from discourse in narrative, 
Narrative Communication Strategies

according to Barthes (1975) is "narration" and is meant to probe the authors intended meaning. Again Barthes (1975) utilizes two systems to decipher "narration proper" or the narrators code: the first is personal (first person), the second is impersonal or apersonal (third person) (p. 262). By integrating linguistic analysis of function (the essence of the plot), action (relationship of characters with other characters and objects) and narration (authorial intent), Barthes (1975) argues that an overarching understanding of narrative communication exemplified in a discourse can be deciphered.

\section{The Proposal Narrative}

Though very focused, Barthes' tools of analysis still require an interpretive framework by which they can be used to answer the questions asked in the literature review regarding narratives within funding proposals, as well as speak to the overarching research question. Clarke (2001) has outlined a clear method for the organization of funding proposals using a narrative framework. She begins by outlining character and place (setting). The main character or hero of the narrative is usually, of course, the organization seeking funding - but there are also other characters at play in the funding proposal such as the government agency and partner agencies. The sense of place refers to the location of the proposal story (in AMREF Canada's case it is their proposed project area in Ethiopia). From here the narrative within the proposal must follow a story arc that outlines a tension/conflict that must be resolved and even an antagonist (who may not necessarily be a person/human character.) Finally, the narrative is concluded by providing resolution to the tension/conflict that was evident throughout the story arc (this resolution of course being provided by the hero character, the NGO) (Clarke, 2001).

Analysis of the narratives found within the proposal submitted by AMREF Canada 
Narrative Communication Strategies

to CIDA is based on a combination of these two theoretical outlines (Barthes and Clarke) that seeks to answer the key questions asked in the literature review. The linguistic patterns of function (distributional or integrative units), action relationships between characters (subject/object, giver/receiver, adjutant/opposer) and narrative author will be drawn from the proposal utilizing the context set up by Clarke (2001) that outlines systems of narratives within proposals that highlight character, place, tension/conflict, story arc and resolution. 
Narrative Communication Strategies

\section{Data Gathering Methods}

The methods employed to analyze the research question for this project are an amalgamation of approaches drawn from the literature previously discussed and the theoretical framework that was previously outlined. Before outlining the specific methods of discourse analysis that were used for this study, a brief discussion of the choice of organization as well as a rationale for the samples analyzed will be presented. Finally, the methodology for analyzing the samples is explained.

\section{Sample Rationale}

AMREF was chosen as the organizational case study for this project for two reasons. First, the researcher has a relationship with the organization and worked as an intern at the organization's head office in Toronto, Ontario, for several months. This established relationship ensured that gathering of materials for the purpose of analysis would more likely be allowed by the organization in question. The funding proposals submitted by NGOs to CIDA are not generally made public and thus permission was needed to access and discuss the proposal content. Ethics approval was not necessary as long as permission was granted by the organization to use their proposal for research purposes. The second reason for choosing AMREF as the case study is the nature of their organization. By definition they are a non-governmental organization that serves as a branch of a larger international aid organization and thus fit into the category of INGO that was analyzed by the researchers referenced in the literature review. As well, they are an organization that has a long standing relationship with CIDA, the government agency being studied, and a long, successful history of providing development initiatives in Africa that relate to maternal, newborn and child health (AMREF, 2011). Thus they are 
Narrative Communication Strategies

an organization that can arguably serve as a case study for best practices - though this assumption will be further explored in the analysis of their proposal.

The relevance of choosing the proposal AMREF submitted to CIDA in answer to the agency's call-for-proposals for the Muskoka Initiative Partnership Program speaks for itself. However, the choice of which sections within the proposal to analyze required a rationale based on the theoretical framework used for this paper.

The guidelines for the proposal as outlined by CIDA (2010) were followed to the letter by AMREF (and indeed, in the call-for-proposal CIDA makes it clear that any proposal which does not precisely meet the guidelines provided will not be eligible for consideration). Thus the AMREF proposal is organized in the following format:

- Section 1: Introduction

- Section 2: Project Name and Contact Information

- Section 3: Canadian Organizations Eligibility

- Section 4: Project Overview

- Section 5: Project Merit

- Section 6: Financial Information

- Section 7: Supporting Documentation

Since the broad theoretical framework being used for this paper is a study of narrative, clearly only the sections within the proposal that are written in a narrative format needed to be included in the sample studied. Thus Section 1 and Section 2, which are quite brief, and merely provide basic information about AMREF and Section 3, which simply outlines years of experience, revenue sources etc. were not included in the sample chosen. Section 6 and Section 7 are also simply tables and summaries providing overviews of financial information and supporting documentation. Section 4 (Project Overview) and Section 5 (Project Merit), which are also the most in-depth and longest sections, were the broad sample sections chosen for analysis (Appendix I). 
Narrative Communication Strategies

Within Section 4 and Section 5 only certain portions were analyzed, again based on whether or not the sample was formatted as a narrative. The choice of how to designate a sample as being in narrative format was based on the definition of narrative within proposals that was outlined by Clarke (2001). If the sample clearly outlined characters, place, tension/conflict and a resolution of any sort within a designated portion of the section, then they were included in the samples to be analyzed. After breaking down the two sections based on this rationale the samples-to-be-analyzed are as follows:

- Section 4.1: Project Description and Rationale

- Section 4.2: Describe Project Objectives

- Section 4.5: Describe Activities to be Undertaken to Reach Objectives

- Section 5.2.1: Relevance of Results

- Section 5.3.1: Sound Project Design

○ Section 5.3.1.2: How the Project Aligns with the countryies strategy for Maternal and Child Health

- Section 5.3.1.3: Lessons Learned and Best Practices for the sector

○ Section 5.3.1.4: Local Participation and Consultations (see Appendix 1)

\section{Methods for Analysis}

The theoretical framework established by Barthes (1975) for Structural Analysis of Narrative was combined with the strategies for storytelling within proposals outlined by Clarke (2001) for doing analysis of the sample proposal. Though discussion of the analysis that will occur later is a holistic examination of the findings of both methods of analysis, for the purpose of actually going through the sample sections and qualitatively coding the information two separate steps were utilized.

Step 1 was breaking down the chosen samples into examples of narratives as outlined by Clarke (2001), which articulate character, place, tension/conflict and resolution. Highlighting each concept by colour coding the different narrative functions completed this process. Step 2 involved codifying the linguistic patterns of narrative 
Narrative Communication Strategies

outlined by Barthes (1975) found within each sample section by highlighting the functions of individual units within the narrative (to determine the essence of the narrative), the relationship of characters with each other and with the plot, and analysis of the narrator's code (or the authorial voice) evident in the overarching structure of the narrative (see Appendix II).

Analysis of the function of the units within the narrative began by determining whether the sequence of each sentence within the narrative was distributional (complementary and consequential acts naturally leading to the next plot concept) or integrative (relating to character building and setting). After this analysis occurred further breakdown of the functions of the linguistic patterns was possible utilizing the variables for outlining strategy discussed in the literature review. This further analysis will be explained in the results and discussion section.

Analysis of the sphere of actions committed by the characters within the narrative was made simple by the fact that an outline of the characters at play had already occurred in the previous coding process. The next step was evaluating whether the outlined characters were engaging in a subject/object (communicative) action, a giver/receiver (desire) action or adjutant/opposer (ordeal/struggle) action. Finally, the narrative voice, whether personal or apersonal was determined by analyzing the linguistic patterns for referencing the author (or not) throughout the sample (see Appendix II).

\section{Methods for Discussing Analysis}

The themes that were drawn from the analysis outlined in both Step 1 and Step 2 reveal overarching strategies of communication employed by AMREF in their proposal. After the linear analysis of both narrative structure and linguistic patterns, discussion of 
Narrative Communication Strategies

the broad themes drawn from the narratives as a whole (when combining all the different types of analysis together in order to attempt a big picture idea of the communication strategies employed) occurred. This was accomplished by utilizing the three strategic concepts of independence, relevance and power relationship as interpretive tools for the sample narratives. In order to determine the levels of independence, choice of relevance and power dynamics, as well as articulate the Theory of Change employed by AMREF (and specific strategic tactics they used) the call-for-proposal produced by CIDA (2010) was used as a measurement benchmark. Linguistic analysis of the expectations laid out in the call-for-proposals was measured against the coding already performed on the proposal narrative sections. 


\section{Results and Discussion}

Analysis of the seven sample sections followed the pattern outlined in the methods section. Discussion of the analysis that occurred will begin by looking at the results of coding the narrative structure, followed by consideration of the analysis that was done looking at the linguistic structure of the narratives. After discussion of the raw results of both types of coding, themes that outline the communication strategies utilized by AMREF in their proposal (drawn from the coding) will be discussed in relation to the three key strategic categories of independence, relevance and power relationship,

\section{Coding: Narrative Structure}

The narrative structure coding of each of the seven sections studied, followed a similar vein - characters, place, tension/conflict and resolution were apparent in each one. Most characters and places were repeated and evident in many if not each of the sections.

Table 1.1 below outlines the main characters and places mentioned in each section.

\section{Table 1.1: Characters \& Place}

\begin{tabular}{|c|c|c|}
\hline Section & Characters & Place \\
\hline $\begin{array}{l}\text { Project Description \& } \\
\text { Rationale }\end{array}$ & $\begin{array}{l}\text { - International } \\
\text { Organizations (WHO, } \\
\text { UNICEF, UNFPA, World } \\
\text { Bank) } \\
\text { - Ethiopian mothers in } \\
\text { South Omo } \\
\text { - skilled health workers: } \\
\text { nurses, midwives, lab } \\
\text { tech's, community health } \\
\text { workers (CHW's), health } \\
\text { extensions workers } \\
\text { (HEW's) } \\
\text { - District Ministry of Health }\end{array}$ & $\begin{array}{l}\text { - Ethiopia } \\
\text { - South Omo, Ethiopia }\end{array}$ \\
\hline $\begin{array}{l}\text { Describe Project } \\
\text { Objectives }\end{array}$ & $\begin{array}{l}\text { - Urban \& settled } \\
\text { communities } \\
\text { - pastoral regions: }\end{array}$ & $\begin{array}{l}\text { - Urban \& settled } \\
\text { communities } \\
\text { - pastoral region of South }\end{array}$ \\
\hline
\end{tabular}




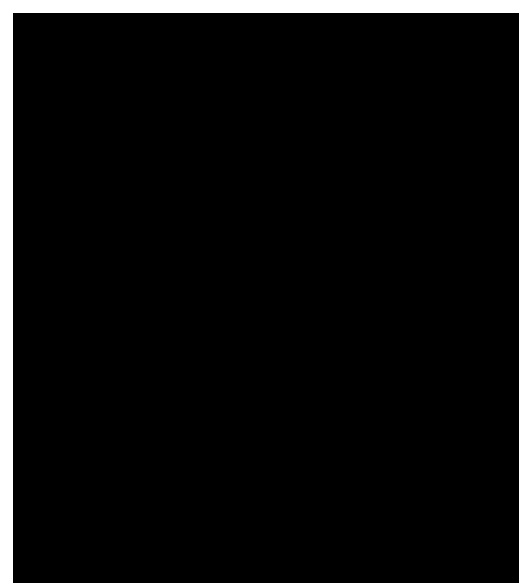

Describe Activities to Reach Objectives

\section{Relevance of Results}

Sound Project Design: Aligning with Ethiopian MNCH Strategies pastoralists or rural communities or pastoralist communities

- South Omo Population

- female South Omo

Population

- health workers: 3

physicians, 1 lab tech, 23

midwives (located in South Omo)

-traditional health providers - AMREF

\section{- Community Based}

Organizations (CBOs)

- Formal and community

health systems

- local and regional

government ministries

- health workers: midwives, lab tech's, nurses, HEWs

- Children, pregnant women and mothers in Ethiopia and South Omo

- Pregnant women and other patients

- Health workers, health personnel

- Mothers and children

- Community influencers and HEWs

- Pregnant women and children in South Omo, Ethiopia

- Government of Ethiopia,

- Ministry of Health

- African Union

- AMREF

- Southern Nations, Nationalities and Peoples Region

- (local) communities - International health development partners: WHO, UNICEF and UNFPA
Omo

- formal health facilities

- 1 hospital (Jinka Hospital)

and 12 health centres

- Ethiopia's peripheral health systems

- Community and formal health systems

\section{- 6 counties of South Omo:}

Benatsemay, Hamer, Malle, Salamago, South Ari and Jinka Town

- higher health facilities

- pastoral areas such as

South Omo

- health facilities

- Southern Nations,

Nationalities and Peoples

Region

- South Omo, Ethiopia 


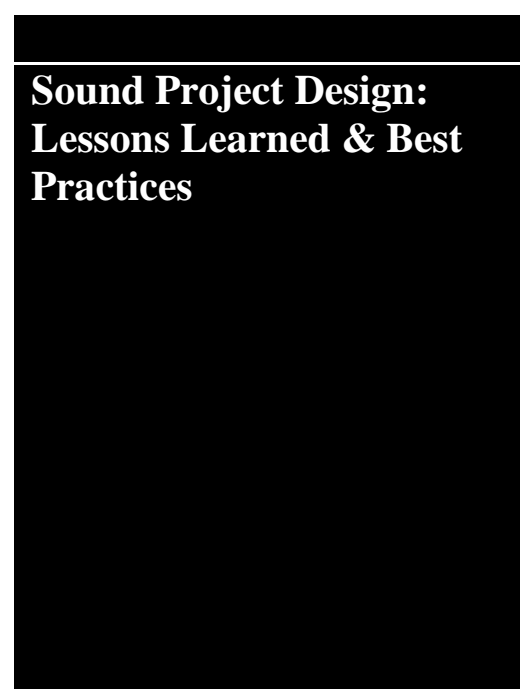

\section{Sound Project Design: Local Participation \& Consultations}

\begin{tabular}{|c|c|}
\hline $\begin{array}{l}\text { - AMREF } \\
\text { - Poor communities } \\
\text { - Formal and community } \\
\text { based systems } \\
\text { - Women in communities } \\
\text { - Similar communities } \\
\text { - Traditional Birth } \\
\text { attendants (TBAs) } \\
\text { - Accessible and respected } \\
\text { health providers } \\
\text { - Removed and underserved } \\
\text { communities }\end{array}$ & $\begin{array}{l}\text { - Sub-Saharan Africa } \\
\text { - Formal and community } \\
\text { based systems } \\
\text { - Similar community (to } \\
\text { South Omo) } \\
\text { - pastoral settings } \\
\text { - Afar, Ethiopia } \\
\text { - Pastoral communities and } \\
\text { resource-poor settings }\end{array}$ \\
\hline $\begin{array}{l}\text { - SNNP Regional Health } \\
\text { Bureau } \\
\text { - AMREF } \\
\text { - Six districts in South Omo } \\
\text { - Community members, } \\
\text { traditional leaders, health } \\
\text { workers, local authorities } \\
\text { - CIDA } \\
\text { - South Omo Health } \\
\text { Department, district health } \\
\text { focal persons, NGO rep's } \\
\text { and AMREF personnel } \\
\text { - Health workers: including } \\
\text { HEWs midwives and TBAs } \\
\text { - Mothers }\end{array}$ & - South Omo \\
\hline
\end{tabular}

A few key themes were evident after considering the coding of characters and places.

Theme 1: Place or location often also simultaneously referred to character(s) or was at least a part of the description of the other. For example South Omo is often referenced both as a geographical location as well as referring to the people, (specifically women and children) who live there. 
Narrative Communication Strategies

Theme 2: Generally the most commonly referenced characters were health care workers - followed by mothers and children (Table 1.1 lists the types of characters referenced in each section, but is not indicative of the amount of times they are mentioned).

The other two measurements of narrative structure, conflict/tension and resolution were more holistic concepts and coding of these categories was done by outlining whole sentences that fit into one category or the other. For example, in section 4.1 after the introductory sentence, all the sentences in the rest of that paragraph relate a tension or conflict; they all explore or list causes of maternal health problems. Meanwhile, in the second paragraph, all the sentences present resolutions (or interventions as AMREF terms them) for reducing disease and improving maternal health (see Appendix II). Interesting themes that came out of this coding exercise are as follows

Theme 3: Almost every sentence could be categorized as either conflict/tension or resolution - indeed, the overarching theme of all of the sections is the fact that resolution of a conflict is being sought after or suggested. For instance in section 5.2.1 addressing how the proposed program responds to local needs, the strategy utilized is to highlight conflicts such as health challenges and poor quality health facilities and suggest that AMREF's response will be offering resolutions that meet these needs (Appendix I). Theme 4: Sentences dealing with conflict/tension generally focused on a few common themes like the lack of infrastructure and health care workers in pastoral communities. An example of this drawn from section 4.2 is, "There remains an urgent need to address the acute shortage of well trained health workers in rural communities to deliver MNCH services" (Appendix I). Meanwhile, sentences dealing with resolution generally focused 
Narrative Communication Strategies

on strengthening health systems by training workers (foremost suggestions), educating the community and providing some medical equipment.

Theme 5: Tensions/conflicts were rarely, if ever, between characters, but rather between characters and situation or characters and place. In sentences dealing with tension/conflict, AMREF does not blame characters for that tension/conflict. Rather, they use neutral descriptors and refer to statements of fact (i.e., there is a conflict), not discussion of responsibility. For example, the opening paragraph of section 5.2.1 focuses on generic tension/conflict issues such as "health challenges," "lack of access" and "cultural traditional practices and beliefs [that] contribute to the lack of health seeking behavior" (Appendix I).

\section{Coding: Linguistic Structure of Narratives}

The analysis of the linguistic structures within the narratives is not as linear as the coding that was previously outlined. Using Barthes' (1975) framework for discourse analysis of narrative, the sample sections were broken down into functions, character relationships and authorial tone.

\section{Functions}

Analyzing whether the functions or units within the narratives were distributional or integrative was a simple matter of analyzing the sentence structure patterns of content in each section. The immediate and obvious result of analysis revealed that most of the functions within the sentences were distributional, meaning they were simply complementary and/or consequential functions (like in section 4.1 where one sentence discusses maternal death in Africa, then the next sentence consequentially leads to a discussion of maternal death in Ethiopia specifically, Appendix I) not indicial or relating 
Narrative Communication Strategies

to nuances such as character development over time and setting up atmosphere and scene (such as, Sally contemplated baking a cake as it reminded her of a memory with a close friend etc.) This kind of narrative is not evident in the samples studied. Considering that these are narratives set within a proposal (not a genre that requires setting very much scene and atmosphere), this is hardly surprising. However, there is still value to be derived from the findings.

In his discussion of distributional functions, Barthes (1975) has developed another layer of analysis to explore the concept more deeply. He further characterizes distributional functions as serving one of a two roles: acting as a catalyst, which is a simply complementary function and essentially fills in the blanks of the narrative form (Sally added baking soda to the cake mix), or serving a cardinal function which is both complementary and consequential at the same time. Cardinal functions provide a deeper meaning within narrative function, in which you must "verify that the action to which it refers opens (or maintains or closes) an alternative directly affecting the continuation of the story, in other words, that it either initiates or resolves an uncertainty (Barthes, 1975, p. 248)." A simple example would be, "Sally hesitated to make the cake as she was torn between reliving an old memory and simply ignoring her feelings and watching a movie. She chose to bake the cake." Such a sentence is complementary to the rest of the (imaginary) story but is also consequential - the choice that Sally makes at this point in the narrative will dictate what direction the story follows next. An example of catalyst and cardinal functions in the samples studied is found in the two paragraphs of section 4.1 (see Appendix II). A cardinal function is evident in the latter part of paragraph 1, describing how maternal health is improving in urban communities but not pastoral 
communities. This is both complementary to the discussion at hand but also consequentially leads to the discussion of interventions that can alleviate this problem, (which occurs in paragraph 2) and sets up a theme of comparing local to urban communities that is evident throughout many of the following sections. Meanwhile the section of paragraph 2 that serves a catalyst function is merely complementary and explains one simple, stand alone concept, i.e., "Strengthening health systems' capacity to deliver effective MNCH services will be prioritized by training midwives..." (Appendix II).

Breaking down the distributional functions of the sample sections into either catalysts or cardinal functions provides valuable analysis of what the key linguistic and sentence structure themes of each narrative section are - the assumption being that cardinal functions will highlight the strategic directions within the narrative that AMREF chose to take. Simply put, the cardinal functions within the samples are the most important concepts that tie the narrative together thematically throughout the proposal and set up the next conceptual step in the story (i.e. what happens next). After drawing out what the cardinal functions in each narrative are (outlined by section in Table 1.2), and focusing on the patterns of either tension/conflict or resolution (discussed in the previous analysis of the narrative structure) within each cardinal function, thematic strategies can be found.

Table 1.2 : Cardinal Functions

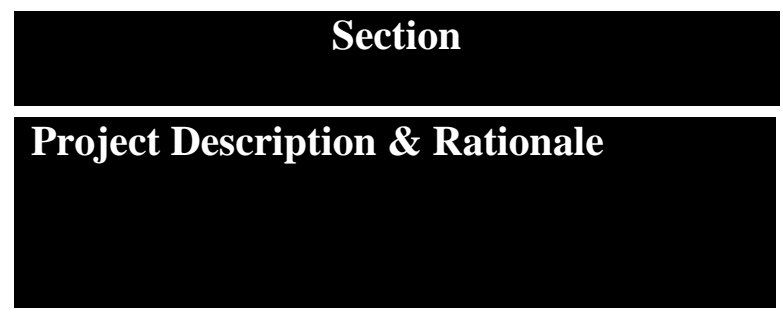

Cardinal Functions*

- Lack of assistance from skilled health workers contributes to high rates of maternal and child morbidity and mortality - the proposed interventions were 


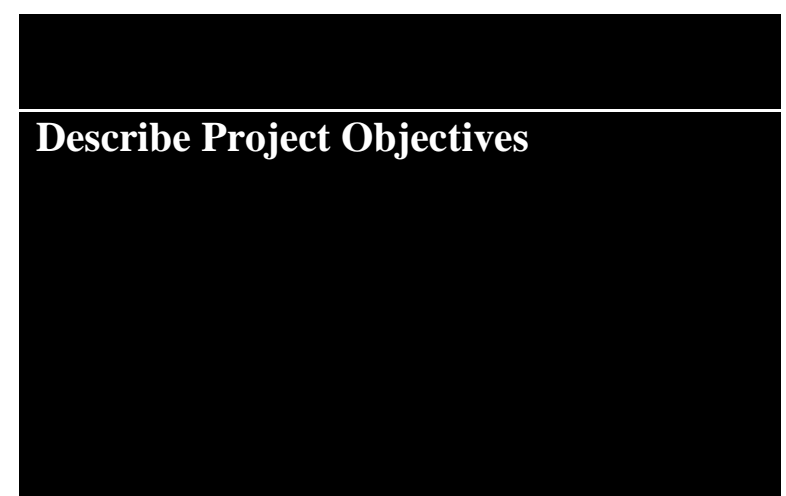

Describe Activities to Reach Objectives

Relevance of Results

Sound Project Design: Aligning with Ethiopian MNCH Strategies

Sound Project Design: Lessons Learned \& Best Practices developed in line with country

development plans and MNCH goals

- South Omo is characterized by socioeconomic underdevelopment and has been marginalized by development policies which respond to urban and settled communities

- urgent need for trained health workers

- Intervention aims to develop a replicable model

- main objective to strengthen formal AND community health systems (integrated approach)

- strengthen health systems includes some key interventions

- health challenges of children, pregnant women and mothers are critical due to lack of access to basic health services and low utilization of available facilities

- project aims to meet the health needs of women and children

- poor quality of current health delivery addressed by more health workers, training and community conversation

- Interventions address needs of margnized groups, focus on women

- overall goal of reducing maternal and child mortality and morbidity; indicators of intervention adopted from national

[Ethiopian] strategies

- AMREF recognizes greatest barrier to good health in poor communities is gap between communities and formal health systems

- in evaluation of similar communities AMREF found role of Traditional Birth Attendants important

- lessons learned and best practices: training and task shifting

- based on understanding of pastoral communities and experience AMREF has incorporated best practices into design of program 
Narrative Communication Strategies

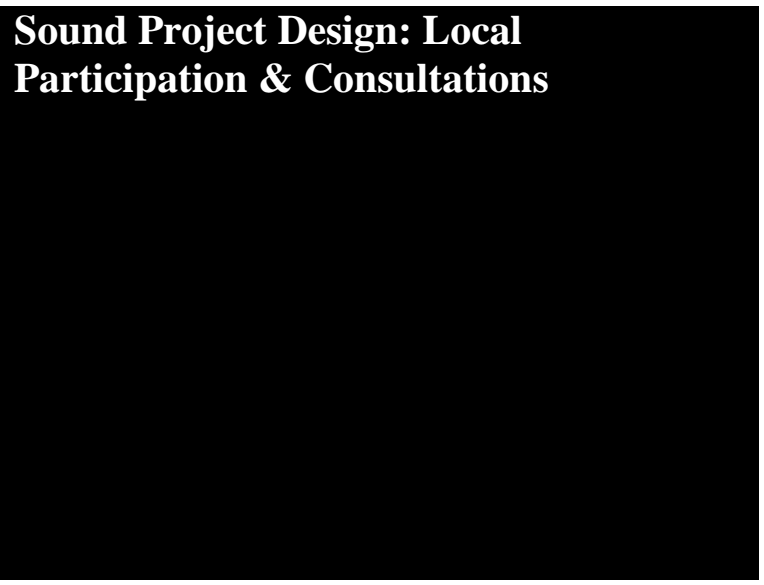

- consultations held in six districts in South Omo with health care workers and authorities

- prioritization of activities discussed with local communities: health care workers, government, NGOs, AMREF personnel - project must emphasize root causes of maternal and child mortality and morbidity to ensure safety of women and children - overall expression and desire to support the project

Two key themes or cardinal functions that AMREF strategically focuses on within their narrative patterns are evident when considering Table 1.2.

Theme 6: The main strategic perspectives (that determine consequent directions or focuses within the narrative) AMREF promotes throughout their narrative are, the lack of health care workers and the disconnect between rural dwellers and health care systems that leaves mothers and children at risk of health care problems.

Theme 7: AMREF is working with national and local governments to develop interventions that are in keeping with Ethiopian $\mathrm{MNCH}$ goals.

\section{Character Actions}

The three categories for analyzing character relationships outlined by Barthes (1975) were used to analyze the different kinds of actions characters engaged in within the narratives studied. Table 1.3 codifies main characters and/or place (as mentioned previously, throughout the narratives explored there was often a fine line separating the two functions) discussed in each of the seven sections studied in this paper, highlighting the key actions directly related to them. 
Table 1.3: Character Actions

\begin{tabular}{|c|c|c|c|}
\hline Section & $\begin{array}{c}\text { Subject/Object } \\
\text { (Communication) }\end{array}$ & $\begin{array}{l}\text { Giver/Receiver } \\
\text { (Desire or Quest) }\end{array}$ & $\begin{array}{c}\text { Adjutant/Opposer } \\
\text { (Ordeal or Struggle) }\end{array}$ \\
\hline $\begin{array}{l}\text { Project } \\
\text { Descriptio } \\
\text { n \& } \\
\text { Rationale }\end{array}$ & $\begin{array}{l}\text { Africa/ } \\
\text { challenge in } \\
\text { reaching MDG } \\
\text { goals } \\
\text { WHO, } \\
\text { UNICEF, } \\
\text { UNFPA, World } \\
\text { Bank/estimate } \\
14000 \text { deaths } \\
\text { related to } \\
\text { pregnancy in } \\
\text { Ethiopia }\end{array}$ & $\begin{array}{l}\text { [AMREF] } \\
\text { interventions/ } \\
\text { in line with } \\
\text { Ethiopian } \\
\text { MNCH } \\
\text { strategies } \\
\text { activities and } \\
\text { indicators/redu } \\
\text { ce HIV, TB \& } \\
\text { Malaria in } \\
\text { pregnant } \\
\text { women } \\
\text { strengthen } \\
\text { health } \\
\text { system/training } \\
\text { health care } \\
\text { workers }\end{array}$ & $\begin{array}{l}\text { Continent } \\
\text { (Africa)/acco } \\
\text { unts for } 40 \% \\
\text { of maternal } \\
\text { deaths } \\
\text { globally } \\
\text { progress } \\
\text { made/but } \\
\text { concentrated } \\
\text { in urban } \\
\text { areas } \\
\text { South } \\
\text { Omo/91\% } \\
\text { women } \\
\text { deliver } \\
\text { babies } \\
\text { without } \\
\text { skilled health } \\
\text { workers }\end{array}$ \\
\hline $\begin{array}{l}\text { Describe } \\
\text { Project } \\
\text { Objectives }\end{array}$ & $\begin{array}{l}\text { South } \\
\text { Omo/character } \\
\text { ized by socio- } \\
\text { economic } \\
\text { underdevelopm } \\
\text { ent } \\
\text { South } \\
\text { Omo/need } \\
\text { trained health } \\
\text { workers in } \\
\text { MNCH } \\
\text { services }\end{array}$ & $\begin{array}{l}\text { female } \\
\text { population/ } \\
\text { served by } 1 \\
\text { hospital \& } 12 \\
\text { health centers } \\
\text { AMREF/goal to } \\
\text { strengthen } \\
\text { Ethiopia's } \\
\text { peripheral } \\
\text { health systems } \\
\text { (5 different } \\
\text { strategies to } \\
\text { strengthen) } \\
\text { [AMREF] } \\
\text { interventions/to } \\
\text { develop a } \\
\text { replicable } \\
\text { model for } \\
\text { improving } \\
\text { MNCH services } \\
\text { AMREF/ } \\
\text { strengthen local } \\
\text { awareness of }\end{array}$ & $\begin{array}{l}\text { region (South } \\
\text { Omo)/margin } \\
\text { alized by } \\
\text { development } \\
\text { policies } \\
\text { focused on } \\
\text { urban } \\
\text { communities } \\
\text { limited } \\
\text { health } \\
\text { workers/depe } \\
\text { nd on } \\
\text { traditional } \\
\text { health } \\
\text { providers } \\
\text { health } \\
\text { centers/no } \\
\text { emergency } \\
\text { obstetric care }\end{array}$ \\
\hline
\end{tabular}




\begin{tabular}{|c|c|c|c|}
\hline & & $\begin{array}{l}\text { MNCH health } \\
\text { care }\end{array}$ & \\
\hline $\begin{array}{l}\text { Describe } \\
\text { Activities } \\
\text { to Reach } \\
\text { Objectives }\end{array}$ & $\begin{array}{l}\text { project/promot } \\
\text { es partnerships } \\
\text { with } \\
\text { community and } \\
\text { local } \\
\text { government }\end{array}$ & $\begin{array}{l}\text { planned } \\
\text { activities/impro } \\
\text { ve maternal } \\
\text { and child } \\
\text { health } \\
\text { [AMREF] } \\
\text { strengthen/for } \\
\text { mal and } \\
\text { community } \\
\text { health systems } \\
\text { [AMREF] } \\
\text { strengthen/heal } \\
\text { th system } \\
\text { through } \\
\text { training } \\
\text { [AMREF] } \\
\text { equip/health } \\
\text { facilities to } \\
\text { improve } \\
\text { MNCH services }\end{array}$ & \\
\hline $\begin{array}{l}\text { Relevance } \\
\text { of Results }\end{array}$ & & $\begin{array}{l}\text {-project/aims to } \\
\text { meet health } \\
\text { needs of women } \\
\text { and children in } \\
\text { South Omo } \\
\text { results/awarene } \\
\text { ss of benefits of } \\
\text { modern health } \\
\text { services \& } \\
\text { strengthened } \\
\text { health system } \\
\text { for pregnant } \\
\text { women } \\
\text { health delivery } \\
\text { system } \\
\text { problems/addre } \\
\text { ssed by } \\
\text { enhancing links } \\
\text { between formal } \\
\text { and informal } \\
\text { systems, } \\
\text { training } \\
\text { additional and } \\
\text { current health }\end{array}$ & $\begin{array}{l}\text { Children, } \\
\text { pregnant } \\
\text { women \& } \\
\text { mothers in } \\
\text { pastoral } \\
\text { areas/health } \\
\text { challenges: } \\
\text { basic health } \\
\text { services, } \\
\text { facilities and } \\
\text { knowledge } \\
\text { health } \\
\text { delivery } \\
\text { system/poor } \\
\text { quality } \\
\text { system } \\
\text { contributes } \\
\text { to low } \\
\text { utilization of } \\
\text { health } \\
\text { services }\end{array}$ \\
\hline
\end{tabular}




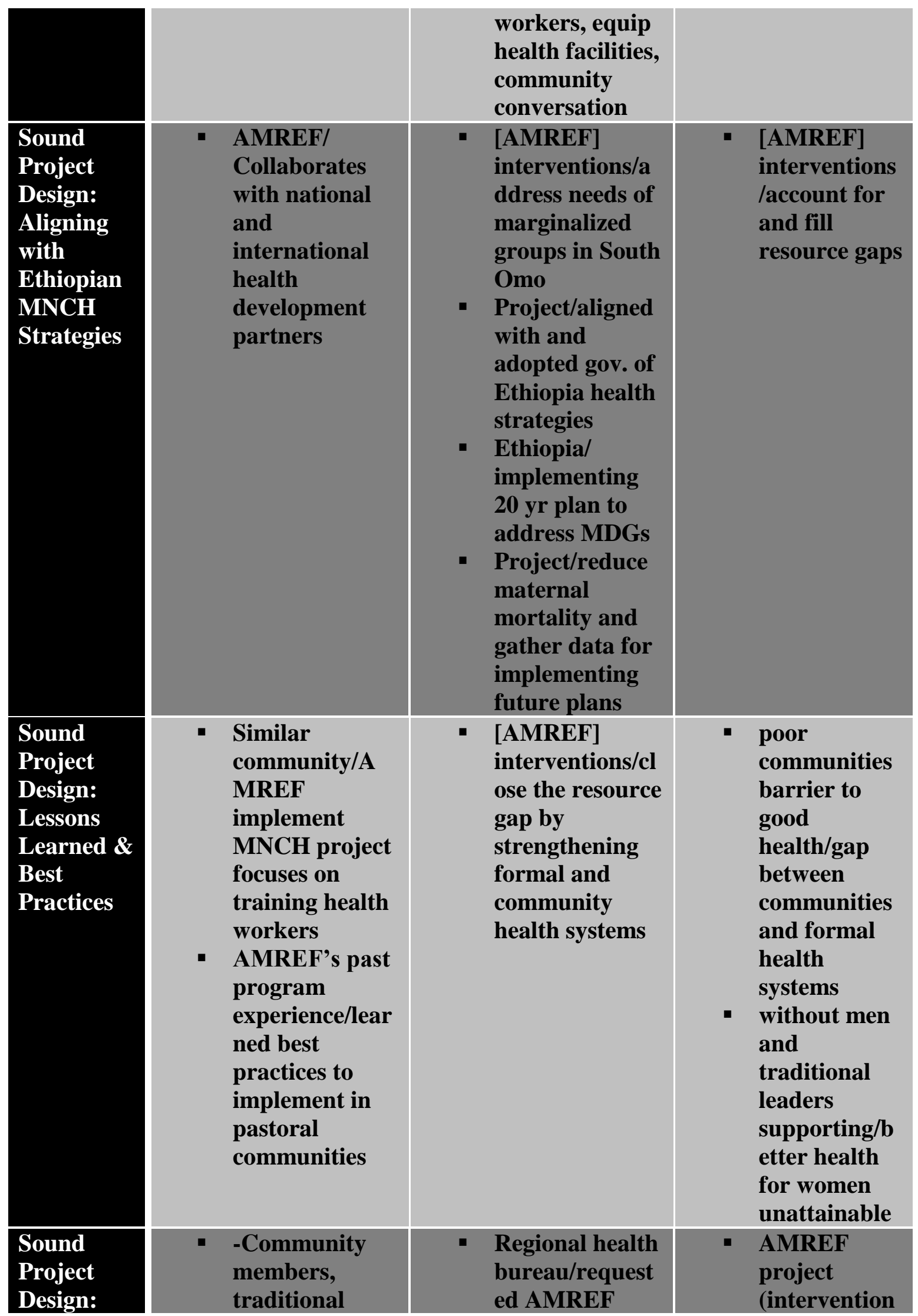



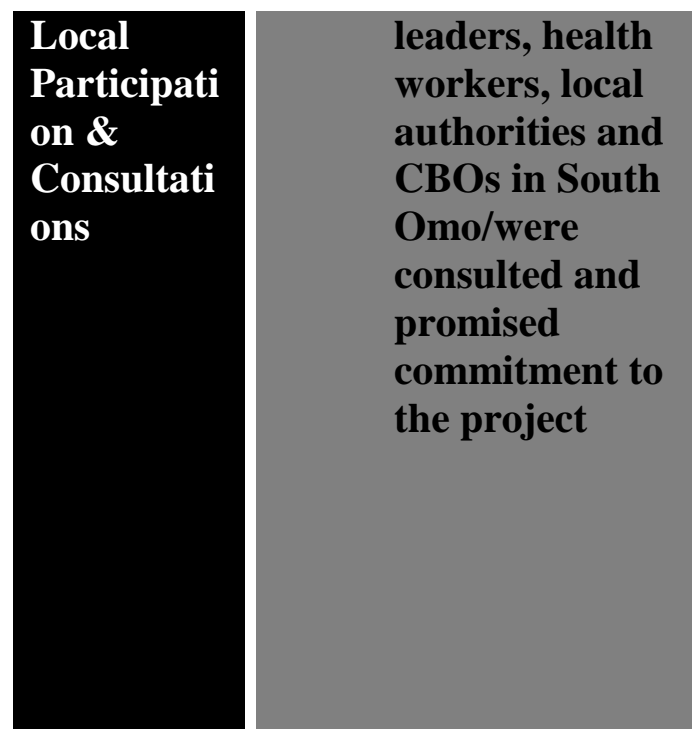

assistance

delivering

MNCH

expansion to

pastoralist communities

- CIDA/Call for proposal resulting in more discussion between AMREF and government identifying MNCH needs

There are a variety of themes that can be drawn from the character/action analysis outlined.

Theme 8: Most of the character actions are giver/receiver (desire or quest) or adjutant/opposer (ordeal or struggle) - the characters in the narrative did not for the most part act out subject/object or communicative roles. For instance, the giver/receiver or desire/quest action roles are generally filled by AMREF providing "interventions" as they like to term it and the adjutant/opposer or ordeal/struggle actions of characters are generally between affected Ethiopians (whether actually referenced as characters, such as women, mothers etc. or place, South Omo, rural communities etc.) and the neutral descriptors of conflict/tension referred to in Theme 6.

Theme 9: Although in the previous coding the finding was that the most commonly occurring character types were health care workers (in regards to both what is needed in conflicts/tensions and who serve to provide resolutions), the most common type of character found at the center of action relationships is overwhelmingly AMREF. They are 
Narrative Communication Strategies

usually the "giver" in the giver/receiver relationship or sometimes the "adjutant" in the adjutant/opposer relationship, which is in keeping with their hero role in the narrative.

Theme 10: Although AMREF is the implied character at the center of most action relationships, often they are not referred to directly - rather the words "intervention" or "project" are used as active subjects to describe the work or perspective of the organization. This final theme leads to a discussion of the narrator's code.

\section{Narrator's Code}

To determine whether personal or impersonal narrative voice was utilized throughout the sample sections, a linguistic analysis of reference to author (or not) was carried out. The first step in determining author's voice was searching for any mention of the known author of the document (AMREF). As can be seen from the research previously discussed, the organization is referred to throughout many of the sections. The question that arose from this finding though was whether or not the use of the organization's name was personal or apersonal.

As Barthes (1975) suggests, when a personal narrative voice is utilized the narrative "is then no more than the expression of an I who exists independently of it" (Barthes, 1975, p. 261). Whether written in the first person or the third person ( $I$ or he/she/they) the authorial voice is clear - you know exactly who is speaking and thus you determine the narrative code based on your understanding of who the author is and what their mandate is. Though AMREF is always referred to in the third person, and though they never use personal pronouns such as "we" to discuss their intent, it is still clear that the motivation evident in the narrative is tied to and a product of a specific author. The use of AMREF's character, always either in a presenting or problem-solving (resolution) 
role, also makes it clear that the organization is the specific author of the document. For example, everything presented in the narrative, be it information about South Omo, discussion of health needs or introduction of other characters is clearly done from the AMREF perspective.

\section{Further Discussion}

Drawing on the ten themes (see Table 2.1) found during analysis of the narrative samples, it is now possible to highlight specific communication strategies used by AMREF in their proposal by discussing how these themes relate to the strategic variables of independence, relevance and power relationship. Discussion of these overarching strategies will include focusing on the specific tactics employed to support these strategies (evident in the previously mentioned themes). Finally, the nature of the relationship between AMREF and CIDA, which has been designated as the marker for determining the success of the proposal submitted for Muskoka Initiative funding, will be explored.

Table 2.1: Themes

\section{Type of Analysis}

\section{Characters}

Conflict/Tension \& Resolution

\section{Themes}

Theme 1: place and location simultaneously refer to character

Theme 2: common characters - health care workers then mothers and children

Theme 3: almost every sentence highlighting conflict/tension or resolution

Theme 4: conflict/tension - lack of infrastructure and HCW, resolution - strengthen health systems by training workers

Theme 5: conflict/tension not between characters, but between characters and situation or characters and place Theme 6: Main strategic perspectives are - lack of HCS, disconnect between rural dwellers and health care systems causes health risks

Theme 7: AMREF works closely with Ethiopian MNCH 


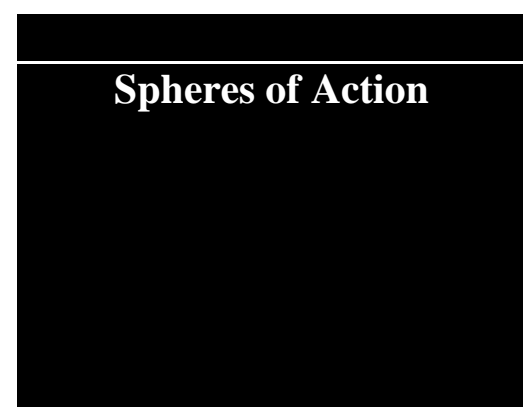

\section{mandates}

Theme 8: most action relationships giver/receiver or opposer/adjutant

Theme 9: Most common character at center of action relationships AMREF

Theme 10: AMREF is implied character at center of most action relationships (authorial voice is clearly them) but not directly referenced

To analyze the themes against the three strategic variables it is necessary to bring in the call-for-proposal developed by CIDA (2010) as a comparative document. To begin gauging the amount of both independence and relevance employed by AMREF as a strategic variable, we will refer back to a question asked in the literature review: Does CIDA support the overall strategic perspective of the organization (being, the provision of means for communities to care for their own health needs in the long run and the global mobilization of people and resources), which would lead to the supposition that they have an "allied" relationship?

\section{Aligning Independence \& Relevance}

Attempting to decipher how well the AMREF mandate aligns with CIDAs mandate in the narrative sections analyzed was determined by comparing the characters and/or place that AMREF focused on with the characters/and or place highlighted in the call-for-proposal as well as determining whether the three strategic focuses AMREF utilized are in keeping with the strategic demands in the call-for-proposal.

As mentioned when discussing Theme 1 and 2 (see Table 2.1) character and place within the proposal were often indicative of the same concept. For instance, when writing, "the region [South Omo] has been marginalized by development policies which respond to the needs of urban and settled communities (CIDA, 2010, p. 4)," although AMREF is referring to a place, the role of the place (by inference, not linguistics) is in 
Narrative Communication Strategies

reference to the character of pastoral communities who live in the region South Omo. Though at first glance this transition of meaning might seem to diminish the status of the characters in question, because of the nature of the narrative developed for funding proposals that is arguably not the case. Clarke, (2001) writes that it is important for researchers to establish place early on in a narrative because funding is almost always directed at recipients within a specific geographical area. Thus, the importance and relevance of highlighting and referencing place within such a narrative is arguably almost as important as the recipient demographics within that geographical area. Indeed, the strategy is accomplishing two purposes at once - as both character and place are wrapped up in and referenced in one term.

In the use of this strategy, AMREF is in keeping with the mandate and linguistic patterns put forward by CIDA (2010) in their call-for-proposal. Though, of course, it would be ridiculous if AMREF did not meet the simple CIDA (2010) requirement that potential programs be located in specified eligible countries (of which Ethiopia is one), when CIDA outlines their expectations for proposals (determined by looking at the key characters and cardinal functions within the call for proposal) they themselves often refer to characters based on geography, not role (i.e. mothers).

In regards to character focus, although women and children and pastoral communities are mentioned quite often as recipients in the proposal, the most common characters identified are health care workers (Theme 2). This strategy is in keeping with AMREF's focus on training community health care workers as a main, sustainable solution for reducing illness. 
Narrative Communication Strategies

When considering the themes evident in the cardinal functions from Theme 3 to 5 (which often highlighted health care worker characters), it is clear that within their proposal AMREF is staying true to their mandate to reduce maternal and child mortality by ensuring better health services are available to them. "The health challenges of children, pregnant women and mothers in Ethiopia are critical due to the lack of access to basic health services, low utilization of the available facilities, lack of trust in the quality of services and lack of knowledge (AMREF, 2011, p. 6)." This perspective is highlighted repeatedly with the same characters and resolutions throughout the narrative samples studied.

When questioning whether this mandate is in keeping with CIDAs, it seems at first that AMREF is both developing communication strategies based on their organizational mandate (outlined previously in their mission statement and discussed in the literature review section exploring Musambira's (1997) NGO categories), while fulfilling at least some of the broad expectations of the call-for-proposal. Three key themes are highlighted by CIDA in their thematic profile: strengthening health systems, improving nutrition and addressing leading diseases and illnesses that are killing mothers and children. AMREF is pointedly focused on the first theme (in keeping with their mandate) and by extension also focused on the third theme, as it is implied that better health systems and trained health workers are the key to addressing leading diseases. However, none of the cardinal functions, key character action relationships (Themes 6 to 10) or resolutions to tension/conflict are focused on or related to improving nutrition.

Thus it seems AMREF is maintaining independence in regards to mandate: they focus specifically on the aspects of the call for proposal that are in line with their own, 
Narrative Communication Strategies

but put far less energy and focus on the key paths that are not. In regards to relevance (who an NGO claims responsibility for and who helps guide their vision) there is less discrepancy between AMREF's mandate and CIDAs. CIDA makes it clear in their callfor-proposal that they expect programs that highlight local communities, both in terms of needs and as partners. For instance, in section 5.2.1 of the call-for-proposal outlining expected results CIDA references that a demonstration of whom the initiative will benefit (clearly women and children) and demands "relevant links to national, regional or area strategies" and demonstration that "key stakeholders support the project" (Appendix III).

This perspective is in line with AMREF's broad organizational mandate.

Character analysis, analysis of functions and analysis of tension/conflict and resolution (Themes 1 -10) all reveal that the actors AMREF highlight as relevant to their organization and goals are local communities and governments. For instance, almost all characters other than broad international organizations (discussed in Table 1.1 and 1.3) are Ethiopian, be it women and children or pastoral communities in need (conflict/tension characters) or health care workers and local, government partners (who provide the actual resolution).

The fact that local peoples serve as the actual tools and implementers of resolution also speaks to this mandate of relevance. Although authorial intent on the part of AMREF is personal, they keep actual reference to themselves out of the discussion of solutions (as mentioned in Theme 10). They are the key character in giver/receiver action relationships (Theme 9), but health care workers, followed by women and children, are the most commonly referenced characters in the analyzed sections (Theme 2). This reveals a 
Narrative Communication Strategies

strategy of maintaining an overarching role in facilitating their program, but linguistically focusing relevance on local players.

\section{Gauging Power Relations}

Gauging power relations found with the narrative samples is far more nuanced than simply determining independence or relevance. Using the linguistic structure of narratives analysis to gauge successful communication strategies at play in the power relations between AMREF and CIDA, a key question arose that relates back to relevance: Does AMREF position itself as an ally with CIDA and the Government of Canada's mandate?

To determine the answer to this question, it was necessary to again return to the call-for-proposals, specifically to section 5.1 regarding "Relevance to CIDAs Mandate and Coherence with Government of Canada Policy," which is one of five criteria on which the proposals are judged (CIDA, 2010, p. 8). The specification of what CIDAs mandate and Government of Canada policies are, however, is vague. Although all the other key paths outlined by CIDA in the call-for-proposal relate to health specific initiatives, the singular mandate they refer to in this section is poverty reduction. The entire mandate of the rest of the call-for-proposal when looking at key themes is directly related to initiatives that improve quality of life, i.e., provide better health care facilities, improve nutrition and stop disease. Though these are necessary goals that alleviate the effects of poverty, arguably, they do not speak specifically to reduction of poverty.

It is necessary to probe deeper within the call-for-proposal to determine in what way CIDA expects this mandate of poverty reduction to be fulfilled. The answer can be found by looking at the cardinal functions outlined by CIDA when they provide specific 
guidelines for project principles and management (Appendix III). Key linguistic indicators that serve as the cardinal functions in the sentences analyzed highlight exactly how CIDA expects the projects to be run. These expectations indicating process relate far more to the concept of poverty reduction than the key paths. For instance, the cardinal functions in the section outlining principles that support the G8 Muskoka initiative are outlined in Table 2.2.

Table 2.2: Cardinal Functions in Call-for-Proposal

\begin{tabular}{|c|c|}
\hline Section & Cardinal Functions \\
\hline $\begin{array}{l}5.1 \text { Principles of the G8 Muskoka } \\
\text { Initiative: Maternal, Newborn and } \\
\text { Under-Five Child Health }\end{array}$ & $\begin{array}{l}\text { - Sustainability of results } \\
\text { - Building evidence-based } \\
\text { interventions } \\
\text { - Focusing on countries of greatest } \\
\text { need } \\
\text { - Supporting country-led national } \\
\text { health policies that are locally } \\
\text { supported } \\
\text { Increasing coherence, through } \\
\text { better coordination and } \\
\text { harmonization } \\
\text { - Improving accountability } \\
\text { - Strengthening monitoring, reporting } \\
\text { and evaluation }\end{array}$ \\
\hline
\end{tabular}

Requiring sustainable programs that are monitored and evaluated and choosing countries based on greatest need is far more indicative of principles that would reduce poverty over than time and thus it seems the expectation of fulfilling CIDAs mandate for poverty reduction is more nuanced than simply fulfilling the basic program requirements of improving MNCH services. The implication is that, even if a funding agency develops a fantastic program that meets the needs of the local community it is servicing, to be awarded this funding the agency must make that program sustainable over the long term 
Narrative Communication Strategies

(leading to poverty reduction) and the agency must evaluate and provide proof of this.

The goal then is not just to provide basic emergency health services, it is to provide the community with the tools and training to decrease poverty and improve their standard of living. A very familiar concept, this perspective is in keeping with Musambira's (1997) second category of NGO, Economic and Social Community Development, within which AMREF fits.

To return to the question of power relations then, as this has been more of a conversation regarding relevance, the question that arises is, does AMREF (in its supplicant role) respond to CIDAs implied expectations for poverty reduction such as monitoring, reporting and evaluating their proposed program? Though their initiatives do broadly speak to the principles CIDA is looking for, AMREF does not specifically focus on proving sustainability and workability of their proposed program. They do refer to previous successes and experiences. In section 5.3.1.3, for instance, they spend more time reinforcing local (note reference to place and character simultaneously) characters (again, whether those in conflict/tension, like mothers in need, or those providing resolution, like health care workers) rather than referencing the review and monitoring that would likely be the role of their own character (the hero).

In this power dynamic, AMREF, the supplicant, is as an organization positioned in exactly the right category of NGO (Economic and Social Development). AMREF's organizational perspective is also CIDAs organizational perspective on preferred outcomes. Generally AMREF fulfills the supplicant role they must play by virtue of the fact that their organizational mandate is in keeping with CIDAs. Perhaps then, this is 
Narrative Communication Strategies

what allows them to veer from the more nuanced expectations of CIDA in regards to implied sustainability measurements.

A final marker for measuring the power relationship between AMREF and CIDA is to consider the simple linguistic analysis of the action relationships between AMREF and CIDA that is evident in the funding proposal. AMREF rarely refers to CIDA specifically and even more rarely refers to CIDA in relation to their organization. One exception is in the Sound Project Design: Local Participation and Consultation section where AMREF outlines the process by which they came to submit their proposal. In this section AMREF refers to a framework upon which the proposal is based that reviewed “CIDAs MNCH priorities and expected deliverables,” (AMREF, 2011, p. 21). This reference comes after a lengthy narrative outlining local and national partners in Ethiopia with whom AMREF was working on producing this project before even answering the call-for-proposal.

The inference here is that AMREF is producing an "intervention" (as they term their project throughout the proposal) in keeping with CIDAs main priorities, but they trust their own expertise (outlined in previous sections of the proposal) and develop a program where the specific activities are based on a previously established understanding and relationship of the Ethiopian context. Again, AMREF fulfills the broad supplicant role but uses their own expertise when promoting their proposed program through narrative. 
Narrative Communication Strategies

\section{Conclusion}

The concluding question then is - is AMREF in opposition to, subjugated to or attempting to work in collaboration with CIDA? Brown and Troutt (2004) imply that successful NGO-government relationships (for both the mandate of the NGO and of the government) occur when the two are working cooperatively and in collaboration (a rather logical suggestion). They gauge cooperation based on three factors, whether the NGOs expertise is reflected in the program, if the NGO knowledge and skill to provide effective programming and whether ambiguity and uncertainty are minimized to reduce costs. The last factor is less applicable as this program is still in the proposal stages with CIDA, but much of the Further Discussion section of this paper has highlighted the juxtaposition of AMREF's mandate and ensuing communicate strategies evident in their narrative with CIDAs expectations. AMREF's experience and expertise (leading to the assumption they can provide effective programming) is almost a given in their proposal. They focus on the characters, conflicts/tensions and resolutions that are related to the local needs of South Omo residents, especially women and children. This focus on the community is in keeping with the concept of building sustainable communities and fits with CIDAs broad mandate and perspective.

The conclusion of this discussion is that there is enough give and take between AMREF's proposal and CIDAs call-for-proposal for AMREF to at least partially meet CIDAs expectations. AMREF attempts to maintain independence in terms of who and what they focus on and how, and choose to focus relevance on local characters, which happens to be in keeping with CIDA mandates. In terms of power relations with CIDA, AMREF seeks a collaborative relationship. They meet the broad requirements expected 
Narrative Communication Strategies

of them, as they play the supplicant character in relation to CIDA, but their specific focus is not based on meeting expectations only - they trust themselves and their knowledge to build a program that is successful.

\section{Best Practices}

Drawn from the Results and Discussion section, the best practices in regards to successful narrative communication strategies relate back to the themes found in analysis of the sample sections and findings based on questions that developed from the literature review. Some best practices outlined are broad theories for communication as a holistic strategy and some are specific tactics.

\section{BP 1.}

Successful relationships between NGOs and government are collaborative and respect the expertise and skill of the NGO in the field.

\section{BP 2.}

In a Canadian context, specifically in regards to CIDA, some independence can be maintained by NGOs in regards to perspective and focus in funding proposals if their overarching organizational category and mandate matches that of CIDAs.

\section{BP 3.}

The power relationship between NGOs and CIDA is always tilted in favour of the government organization, and the NGO must meet all the technical requirements and expectations outlined in calls-for-proposal. However, if success is based on collaboration, which respects the expertise and experience of the NGO, then they should prove this by maintaining a connection and focus with their organizational mandates. 
Narrative Communication Strategies

\section{BP 4.}

Referencing place and character synonymously within a narrative is a strong communication strategy when focusing on a specific geographic area because it highlights both the relationship of characters to their space and geographical location in one go.

\section{BP 5.}

When using a personal authorial voice, it is not necessary to refer to oneself within a narrative specifically. The implication of the authorial voice allows for more focus on the characters within the proposal for who the project is being created.

\section{BP 6.}

When discussing tension/conflict focus it is important not place blame or responsibility for the problems being addressed on characters (a practice discussed in Theme 5), but rather on situation and neutral concepts like lack of access. Arguably this practice allows the NGO to maintain a neutral stance that implies they will work closely with all necessary parties - even those who might be causing the problems. For instance, in section 5.2.1, one hindrance to health education that is mentioned is "cultural traditional practices and beliefs." The people who hold and perpetuate these beliefs are likely the ones who an NGO would need to work with to enact change.) 
Narrative Communication Strategies

Appendix I - AMREF Proposal Sections

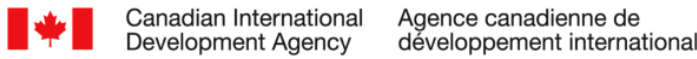

PWCB Partners for Development: Application Form

\begin{tabular}{|l|l|l|}
\hline $\begin{array}{l}\text { 3.3.1.5 Annual revenue sourced from other levels of Canadian } \\
\text { government }\end{array}$ & $\mathbf{\$ 5 , 6 0 0}$ & $\mathbf{0 \%}$ \\
\hline 3.3.1.6 Other sources of Canadian revenue & $\mathbf{\$ 0}$ & $\mathbf{0 \%}$ \\
\hline 3.3.1.7 Annual revenues from non-Canadian sources & $\mathbf{\$ 0}$ & $\mathbf{0 \%}$ \\
\hline 3.3.1.8 Total annual revenues & $\mathbf{\$ 1 , 3 9 6 , 2 8 9}$ & $\mathbf{\%}$ \\
\hline
\end{tabular}

\subsubsection{Other Types of Canadian Support}

3.3.2.1 Number of Volunteers in Canada

34

(Volunteers must have provided an average of 6 hours or more a month to the organization to support its activities, its development work or fundraising activities.)

3.3.2.2 Number of Members in Canada

0

(Members must have paid a membership fee, if applicable)

3.3.2.3 If applicable, other quantitative measures of Canadian support for the organization (describe support and number of Canadians involved annually). If not applicable, enter N/A.

Enter information on in-kind donations. N/A

\section{SECTION 4: PROJECT OVERVIEW}

\subsection{PROJECT DESCRIPTION AND RATIONALE}

Maternal, Newborn and Child Health (MNCH) is unquestionably one of Africa's largest challenges in reaching the UN Millennium Development Goals (MDGs) for 2015. The continent accounts for $20 \%$ of global births, but $40 \%$ of maternal deaths, most of which are preventable with adequate health care. A 2010 report by WHO, UNICEF, UNFPA and the World Bank estimated that in Ethiopia (a CIDA priority country), 14,000 women died in 2008 from causes "related to, or aggravated by, pregnancy or its management," including childbirth. While progress has been made on under-five and maternal mortality targets, improvements are concentrated in urban areas. In Ethiopia's remote and underserved pastoral region of South Omo, close to $91 \%$ of women deliver at home without the assistance of a skilled health worker, contributing to high rates of maternal and child morbidity and mortality.

The proposed interventions are developed closely in line with Ethiopia's Health Sector Development Plan (HSDP) and National MNCH Strategy. Activities and indicators are adopted directly from the Strategy, and will include reducing the prevalence and incidences of HIV, TB and malaria among pregnant women and children. Strengthening health systems' capacity to deliver effective $\mathrm{MNCH}$ services will be prioritized by training midwives, Health Extension Workers (HEWs), nurses, lab technicians and Community Health Workers (CHWs). This approach will link formal and community level health systems to increase integration of service delivery. Health care workers will be trained on Community-Based Health Management Information Systems (CBHMIS), increasing quality data collection and documentation. Nutrition will be provided to improve health indicators of neonates and children under five. Working with the District Ministry of Health, the project will extend and improve existing initiatives and complement the pastoralist Health Service Extension Program (HSEP). All these activities are informed by Canada's Muskoka Initiative on Maternal, Newborn and Child Health.

3/35
PARTNERS FOR DEVELOPMENT - DEVELOPMENT PROJECT

\section{Canadă}




\section{PWCB Partners for Development: Application Form}

\subsection{DESCRIBE PROJECT OBJECTIVES}

The remote pastoral region of South Omo is characterized by socio-economic underdevelopment. The region has been marginalized by development policies which respond to the needs of urban and settled communities. In terms of health services, due to the limited number of health workers, pastoralists are forced to depend mainly on traditional health providers who lack formal training and are not linked to formal health facilities and referral systems.

There remains an urgent need to address the acute shortage of well trained health workers in rural communities to deliver quality $\mathrm{MNCH}$ services. In South Omo, the total population of 629,500 , of which 314,966 are female, is served by only 1 hospital and 12 health centres - a ratio that is significantly below the national average. Currently, only 3 physicians attend to the entire zonal population $(1: 209,801)$ while 1 laboratory technician serves nearly 22,000 people. There are only 23 midwives who have 2 or fewer years of training. None of the health facilities, except Jinka Hospital, provide emergency comprehensive obstetric care - resulting in nearly all births taking place in the home without a skilled health worker and leading to complications.

AMREF's primary goal is to strengthen Ethiopia's peripheral health systems to address the challenges in delivering appropriate and effective $\mathrm{MNCH}$ services to pastoralist communities. The project's specific objectives in South Omo include:

Increasing the proportion of pregnant women accessing maternal health services within their district from trained health workers;

Increasing the proportion of health facilities providing comprehensive health care, including laboratory services, IMNCI and treatment for major communicable diseases;

Increasing the proportion of community members actively denouncing harmful traditional practices such as infanticide;

Strengthening the referral and health management information system, including maternal mortality auditing (data is currently not available at the regional or zonal level); and

Reducing the proportion of children and mothers suffering from nutritional deficiencies that affect safe childbirth and child development.

These are all factors identified in Canada's Muskoka Initiative on $\mathrm{MNCH}$ as contributing to the failure to meet MDG 4 and MDG 5. This intervention further aims to develop a replicable model to accelerate efforts to improve access to maternal health services in South Omo. It seeks to develop innovative methods to bring health care closer to these communities by strengthening and integrating the community and formal health systems. Additionally, AMREF will strengthen local capacities to enhance community awareness and delivery of and access to comprehensive, quality $\mathrm{MNCH}$ health care. AMREF views communities not as mere recipients of services but active participants in the delivery of health care - leading to empowerment and sustainability.

\subsection{DESCRIBE EXPECTED RESULTS (OUTPUTS AND OUTCOMES) AND QUANTITATIVE INDICATORS}


Canadian International
Development Agency $\begin{aligned} & \text { Agence canadienne de } \\ & \text { développement international }\end{aligned}$

PWCB Partners for Development: Application Form

members about environmentally friendly interventions.

Qualitative indicators include: Presence of a strategy designed to reach the segment of the population in operation areas; collaboration between the project's partners; activities carried out; participation level of communities and government partners in project activities; participation of males in reproductive health issues; and participation of communities in environmentally friendly interventions of the project.

Key results at the intermediate outcome level include: The successful targeting of marginalized communities; reduced incidence of major health problems; and the efficient and effective implementation of project activities within the framework of CIDA's cross-cutting themes of improved gender equality and environmental stewardship, which will also be assessed using indicators. These include: qualitative data on the opinions of beneficiaries; opinions of local health centres; perceptions of and descriptions made by community members in target areas; and overall achievement of project results.

\subsection{DESCRIBE ACTIVITIES TO BE UNDERTAKEN TO REACH OBJECTIVE(S)}

The activities below are designed to accelerate the objective of improving maternal and child health in 6 counties of South Omo: Benatsemay, Hamer, Malle, Salamago, South Ari and Jinka Town. The main objective is to strengthen both the formal and community health systems using an integrated approach. Through specific planned activities, the project supports the harmonization of various initiatives, including using community-based approaches for $\mathrm{MNCH}$ by promoting partnerships with Community-Based Organizations (CBOs) and relevant local and regional government ministries.

Planned activities are as follows:

\section{1) Strengthening formal and community health systems through training}

Strengthening health systems, both at the formal and community level, involves several key interventions. In this regard, activities include training and re-training health workers - namely midwives, laboratory technicians and HEWs. More specifically, midwives and HEWs will be trained on the treatment of complications that arise during pregnancy and childbirth, collectively known as Emergency Obstetric and Newborn Care (EmONC) in order to provide integrated, comprehensive and quality MNCH services. HEWs will be trained on the provision of PMTCT services, diagnosis, treatment, prevention and control of HIV/AIDS, malaria, TB and waterborne diseases - illnesses pregnant women and children under five are vulnerable to. They will further receive training on HMIS, community-based maternal mortality auditing and harmful traditional practices. Nurses will be specifically trained on safe, clean and instrumental delivery. Lab technicians will be trained to increase quality control of specimens and diagnosis. Lastly, enhancing midwifery skill will be central across the long term training.

\section{2) Equipping health facilities to improve $\mathrm{MNCH}$ services}

Building on the World Bank project that rehabilitated health facilities, three ambulances will be purchased and a dispatch system established in partnership with the government health bureau. 13 health facilities will be equipped with reagents, microscopes and other essential laboratory equipment. Neonatal kits will be provided at higher health facilities. ARI diagnosis and treatment guidelines will also be provided to all higher health facilities.

$6 / 35$

PARTNERS FOR DEVELOPMENT - DEVELOPMENT PROJECT

\section{Canadă}


Canadian International
Development Agency $\begin{aligned} & \text { Agence canadienne de } \\ & \text { développement international }\end{aligned}$

PWCB Partners for Development: Application Form

\subsubsection{Country Specific Annexes}

Please refer to uploaded document

\subsection{PROJECT RESULTS: RESULTS AND OUTCOMES}

\subsubsection{Relevance of Results}

Describe how the initiative responds to an important need that local beneficiaries are seeking support to meet.

The health challenges of children, pregnant women and mothers in Ethiopia are critical due to the lack of access to basic health services, low utilization of the available facilities, lack of trust in the quality of services and lack of knowledge. Cultural and traditional practices and beliefs further contribute to the lack of health seeking behaviour in communities - especially in pastoral areas such as South Omo.

This project therefore aims to meet the health needs of women and children in South Omo. The expected results related to raising awareness of the benefits of modern health services will increase the use of available resources, leading to the overall improvement of maternal and child health. Wider outcomes include a strengthened health system by ensuring improved access to health facilities through expansion of services to the remotest areas and facilitating emergency ambulance transport and referral for pregnant women and other patients.

The poor quality of the current health delivery system, which indirectly contributes to low utilization of health services, will be addressed by: enhancing linkages between the formal and informal systems; training additional health workers to meet a severe shortage; improving the knowledge and skills of existing health personnel through training; and rehabilitating and equipping health facilities with acceptable standard equipment. Misconceptions about the causes of ill health and the propagation of harmful traditional practices which hamper the expansion and use of health services by mothers and children will be also be managed by continuous community conversations through community influencers and HEWs.

Overall, project activities will contribute to MDG 3 (Promote Gender Equality and Empower Women); MDG 4 (Reduce Child Mortality); MDG 5 (Improve Maternal Health); and MDG 6 (Combating HIV/AIDS, Malaria and other Diseases).

\subsubsection{Beneficiaries}

\begin{tabular}{|c|c|c|c|c|c|}
\hline \multirow{2}{*}{ Beneficiaries } & \multirow{2}{*}{$\begin{array}{c}\text { Beneficiary } \\
\text { Types } \\
\text { (Direct/Indirect) }\end{array}$} & \multicolumn{2}{|c|}{ \# Adults } & \multicolumn{2}{|c|}{ \# Children } \\
\hline & & Female & Male & Female & Male \\
\hline Pregnant Women & Direct & 18,726 & & & \\
\hline Newborns & Direct & & & 12,976 & 10,618 \\
\hline Children Under Five & Direct & & & 24,345 & 24,341 \\
\hline Community Leaders & Direct & 550 & 450 & & \\
\hline $\begin{array}{l}\text { 5) Health Workers (nurses, } \\
\text { lab technicians, HEWs, CHWs, } \\
\text { midwives) }\end{array}$ & Direct & 595 & 262 & & \\
\hline General Population & Indirect & 132,033 & 132,048 & 108,040 & 108,027 \\
\hline
\end{tabular}

$8 / 35$

PARTNERS FOR DEVELOPMENT - DEVELOPMENT PROJECT 


\subsection{PROJECT RESULTS: PROJECT PLANNING AND DESIGN}

\subsubsection{Sound Project Design}

5.3.1.1 Upload a critical path identifying key steps and benchmarks from date of commencement to completion, including handover date(s) to local partners or authorities. See uploaded document.

5.3.1.2 Describe how the project aligns with the country's strategy for Maternal and Child Health. If not applicable, explain why.

\begin{tabular}{|c|}
\hline $\begin{array}{l}\text { The proposed interventions address the needs of marginalized groups with a focus on the } \\
\text { particular needs of pregnant women and children in South Omo, Ethiopia. As such, they have } \\
\text { been developed to align with and contribute to the National Poverty and Health Strategy of the } \\
\text { Government of Ethiopia. The project specifically feeds directly into the Health Sector } \\
\text { Development Programme (HSDP) 2010-2015, MNCH Strategy and the Plan for Accelerated and } \\
\text { Sustained Development to End Poverty (PASDEP). Ethiopia is currently embarking on HSDP IV, } \\
\text { the final stage of the 20-year plan designed to implement the three health care components of the } \\
\text { MDGs (i.e. reduction in child mortality, improvement in maternal health and prevention, detection, } \\
\text { and treatment of HIV/AIDS, malaria and TB). The Plan has also been designed within the } \\
\text { framework of the African Union's Continental Campaign on Accelerated Reduction of Maternal } \\
\text { Mortality in Africa (CARMMA). }\end{array}$ \\
\hline $\begin{array}{l}\text { With an overall goal of reducing maternal and child mortality and morbidity, the activities and } \\
\text { indicators of AMREF's intervention have therefore been adopted from the aforementioned } \\
\text { national strategies. More particularly, the project will strive to reduce maternal mortality from } 673 \\
\text { to } 267 \text { deaths per } 100,000 \text { live births, and the newborn mortality rate from } 39 \text { to } 15 \text { deaths per } \\
1,000 \text { live births. In addition, the project will generate data to inform the implementation of the } \\
\text { pastoralist Health Service Extension Program (HSEP) as set out by HSDP III. }\end{array}$ \\
\hline $\begin{array}{l}\text { Lastly, the intervention has accounted for the resource gap analysis developed by the } \mathrm{MoH} \text { and } \\
\text { partners. According to the MoH (2010), Southern Nations, Nationalities, and People's Region } \\
\text { (SNNPR) is expected to face the widest resource gap (nearly } 65 \% \text { of resources needed to } \\
\text { achieve targets set to achieve MDGs) and the proposed project locations represent the worst } \\
\text { case scenario. The project therefore aims to fill these gaps to improve MNCH indicators in the } \\
\text { region. To meet its objectives, it is designed in collaboration with local authorities, incorporating } \\
\text { input from communities and harnessing positive cultural practices such as those related to child } \\
\text { nutrition to ensure variety in food sufficient districts. }\end{array}$ \\
\hline $\begin{array}{l}\text { With a history in the country (including experience in the proposed region) and longstanding } \\
\text { partnership with the Ethiopian MoH, AMREF has a thorough understanding of the context, } \\
\text { priorities and strategies. It is therefore uniquely positioned to ensure that its project aligns with } \\
\text { and contributes to national MNCH targets. AMREF further collaborates with national and } \\
\text { international health development partners, including WHO, UNICEF and UNFPA, to ensure } \\
\text { activities are continuously informed by relevant policies and avoid duplication of efforts. }\end{array}$ \\
\hline
\end{tabular}

5.3.1.3 Describe how the approach takes into account the local context, and incorporates lessons learned and best practices for the sector. 


\begin{abstract}
Having implemented community-based health development programmes over the last 55 years in sub-Saharan Africa, AMREF recognizes the greatest barrier to good health among poor communities is the gap between communities and formal health systems. The proposed interventions therefore seek to close this gap by strengthening both the formal and communitybased systems. The activities will address both the supply and demand for health care, emphasize health systems capacity strengthening and promote community participation focusing on ensuring access to and utilization of quality services. They will further address: ineffective referral systems; access to specialist services; the disconnect between the informal and formal health sectors; barriers to collecting, sharing and analyzing information; and guaranteeing that communities (namely women) lend a voice in decision making about their own health.
\end{abstract}

In a final evaluation of an $\mathrm{MNCH}$ project implemented in a similar community, AMREF detailed the important role played by community-based Traditional Birth Attendants (TBAs). The evaluation found that a key strategy to reduce maternal, neonatal and child morbidity and mortality is to provide appropriate training on skilled delivery to TBAs, who are accessible and respected health providers, particularly in remote and underserved communities. It is furthermore crucial to link and integrate TBAs into formal health facilities which are equipped with additional tools and resources to address complex deliveries and care. The study lastly revealed that without the positive involvement of men and traditional leadership, it is virtually impossible to attain better health for women in a pastoralist setting.

AMREF's programmatic experience in this area has resulted in numerous lessons learned and corresponding best practices. For example, utilizing task shifting, which could include training midwives and nurses in Basic Emergency Obstetric and Neonatal Care (EmONC) instead of physicians can have a positive impact on pregnant women and their children. Training clinical nurses to assist with deliveries and strengthening the capacity of low-level health workers was also found to be a vital step in the early detection and management of complicated pregnancies. Furthermore, provision of neonatal kits, especially at the lower level health facilities, has a positive impact on saving the lives of newborns. The evaluation found that traditionally kits received little attention in facilities despite their low cost, adaptability and impact. Neonatal care in general received insufficient attention. Another baseline study for a project in the remote region of Afar, Ethiopia demonstrated that few health workers were skilled in saving newborns by resuscitation, yet it is a skill that can be learned in 30 minutes of training and can have a major impact.

It is with this background, deep understanding of pastoral communities and extensive experience in resource-poor settings that AMREF has incorporated best practices into the design of this project's activities.

5.3.1.4 Provide information on local participation and consultations that have been undertaken to ensure the project is needed and will be supported by the beneficiary community. 
In August 2010, the SNNP Regional Health Bureau requested AMREF's assistance to deliver regional $\mathrm{MNCH}$ expansion to pastoralist communities. Following this request, consultations were held in six districts with community members, traditional leaders, health workers, local authorities and CBOs in South Omo. Discussions highlighted cases of maternal mortality resulting from minor and preventable complications. After CIDA's Call for Proposals was announced, further robust engagement was initiated in November and December and deeper discussions were held with experts from different government departments to identify the critical MNCH needs in the region, gaps in services and potential solutions.

In December, prioritization of activities was undertaken with the South Omo Health Department, district health focal persons, NGO representatives and AMREF personnel in the Omo region. Activities were harmonized with the National Action Plan to ensure they complemented and contributed to national priorities. AMREF also ensured the project aligned with governmental and non-governmental initiatives to reduce duplication, and reviewed CIDA's MNCH priorities and expected deliverables. A clear framework was then developed, which informs this proposed intervention.

Through these local consultations, it was determined that the project would emphasize the root causes of maternal and child mortality and morbidity to ensure the safety of pregnant women and children. Community members, local authorities and traditional leaders all indicated their commitment to the project. Health workers, including HEWs, midwives and TBAs, expressed willingness to be trained so they could provide effective, relevant and appropriate $\mathrm{MNCH}$ services. They also welcomed the prospect of being linked to the formal health system, which is a key step in addressing complicated births - a leading cause of maternal mortality. Moreover, mothers indicated willingness to attend health education sessions. There is an overall expression and desire to support the project and commitment to integrate project activities into the community to support local ownership and sustainability.

\subsubsection{Efficient Use of Budgets}

5.3.2.1 Describe cost effective or innovative methods, steps and approaches that will be undertaken to make the execution of the proposal efficient and effective.

\footnotetext{
As the first step of ensuring AMREF is executing the proposed project efficiently and effectively, AMREF will share office and senior management costs for this project with a current project that is under implementation in South Omo. Moreover, the programme will build upon existing structures and will be situated within the existing health system.
}

Programme activities will be integrated into the district and zonal annual core plan which allows AMREF to align and harmonize the activities in this intervention. Due to a longstanding relationship with the district and zonal authorities, AMREF, wherever possible, will utilize local human and structural resources such as trainers, meeting rooms and technical expertise free of charge or at a lower cost.

Additionally, activities improving referral systems and enhancing ambulance coverage will leverage existing resources from an existing private ambulance firm, the Red Cross and health facility owned vehicles. Most importantly, AMREF will provide training on coordination and maximization of resources.

In terms of project activities, the proposed project will focus on high impact, cost effective 
Narrative Communication Strategies

Appendix II - Example of Coding

\section{SECTION 4: PROJECT OVERVIEW}

\subsection{PROJECT DESCRIPTION AND RATIONALE}

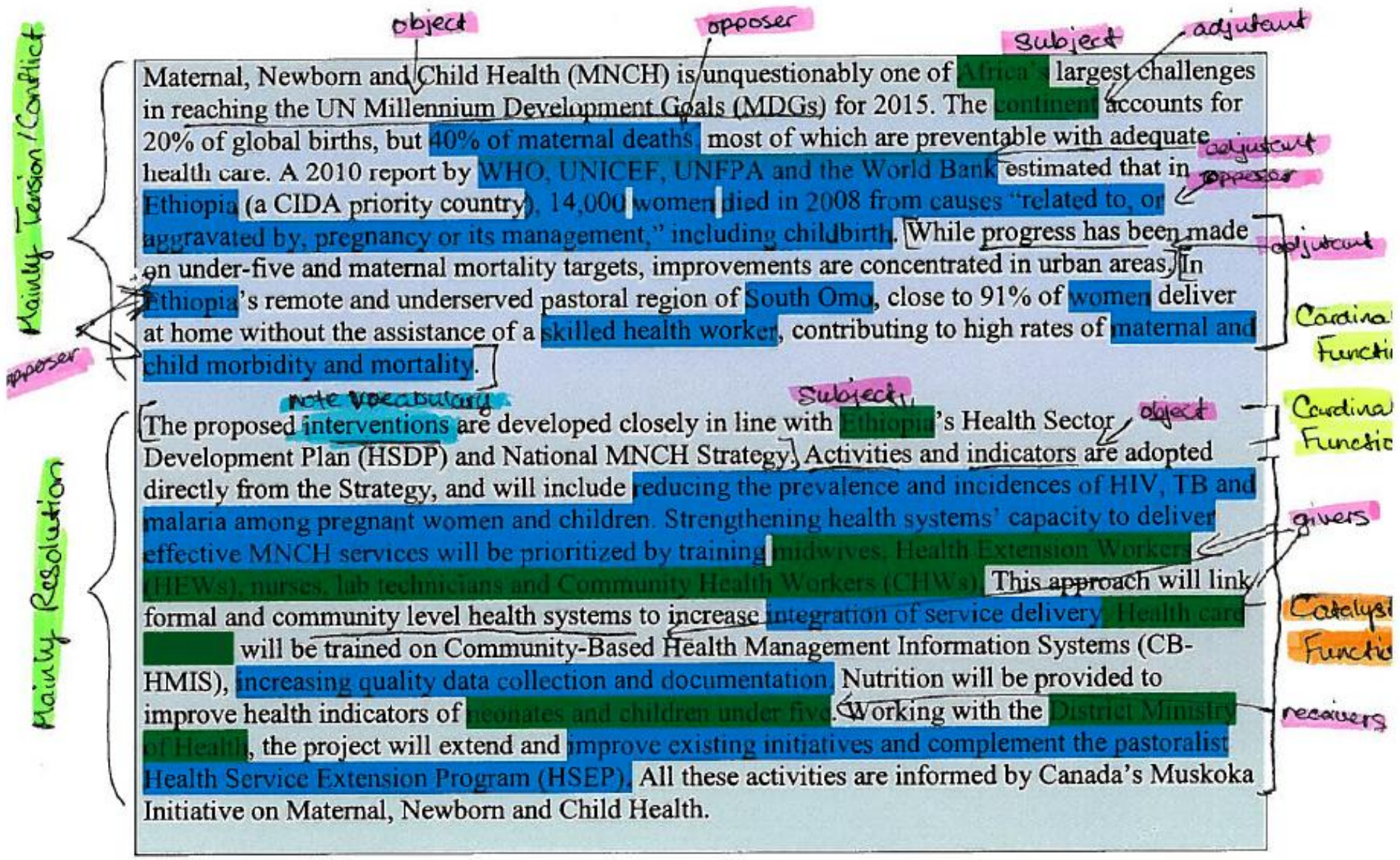

Dark Blue: Characters \& Place

Dark Green: Tension/Conflict \& Resolution

Light Green: Tension/Conflict \& Resolution Themes

Yellow: Cardinal Functions

Orange: Catalyst Functions

Pink: Action Relationships

Light Blue: Other things to note 
Appendix III - CIDA Call-for-Proposal Sections

\subsection{Support of Canadians}

\subsubsection{Revenue Sources}

The applicant must demonstrate that cash or in-kind contributions to the organization originate from Canadian sources other than the federal government. This could include contributions from the private or not-for-profit sectors, individual Canadians or other levels of government. The information in this section is also used to demonstrate that the average total revenue for the last three years is greater than the average amount requested from PWCB.

\subsubsection{Other Types of Canadian Support}

In order for Canadian resources to have a greater impact, PWCB leverages the cash and inkind contributions made by Canadians to the projects of organizations active in international development. Organizations eligible for funding may also demonstrate support of Canadians by the number of volunteers (3.3.2.1) and/or the number of paid-up members (3.3.2.2). If applicable, other quantitative measures of Canadian support can be described (3.3.2.3).

\section{Section 4: Project Overview}

\subsection{Project Description and Rationale}

Section 4 is the Executive Summary of the project. The applicant should provide a concise description of the project and the rationale for the initiatives. This section should describe the development need addressed by the project, its importance, what will be done to meet the need, by whom and who will benefit.

\subsection{Project Objectives}

In this section, list the objectives of the project.

\subsection{Expected Results (Outputs and Outcomes), and Quantitative Indicators}

This section should be a summary of the Description of Results Table (Section 5.2.3.1) describing key results and, what skills and abilities the local partner(s) will have at the end of the project, and the quantitative (measurable) indicators used to measure these results.

Quantitative performance indicators are discrete measures such as a number, frequency, percentile, and ratio. Examples of quantitative indicators are number of health workers trained or number of vaccines administered.

\subsection{Expected Results (Outputs and Outcomes), and Qualitative Indicators}

This section should be a summary of the Description of Results Table (Section 5.2.3.1) describing key results and, what skills and abilities the local partner(s) will have at the end of the project, and the qualitative indicators used to measure these results.

Qualitative performance indicators are measures of an individual or group's judgement and/or perception of congruence with established standards, the presence or absence of specific conditions, the quality of something, or the opinion about something (e.g. the client's opinion of the timeliness of service). Qualitative indicators can be expressed concretely when used to

$7 / 34$

PARTNERS FOR DEVELOPMENT - MUSKOKA INITIATIVE PARTNERSHIP PROGRAM

Canadằ 
report on achievement of results. They should convey specific information that shows progress towards results. Examples of qualitative indicators are beneficiaries' perception of the quality of health services, or the effectiveness of nutritional education programs.

\subsection{Describe Activities to be Undertaken to Reach Objective(s)}

This section should briefly describe the key activities that will be undertaken to achieve the proposed results. The scope of proposed activities should be realistic and clearly linked to the desired results.

\section{Section 5: Project Merit}

PWCB bases its funding decisions on a detailed analysis of proposal's merit against the following principles, as well as an assessment of financial viability (section 6).

\begin{tabular}{|c|c|}
\hline Described in Section & Criteria to Achieve Development Effectiveness \\
\hline 5.1 & $\begin{array}{l}\text { Relevance to CIDA's Mandate and Coherence with Government } \\
\text { of Canada policy: }\end{array}$ \\
\hline 5.1 .1 & - Thematic profile \\
\hline 5.1 .2 & - Geographic profile \\
\hline & Project Results: \\
\hline 5.2 & - Results and outcomes \\
\hline 5.3 & - Project planning and design \\
\hline 5.4 & $\begin{array}{l}\text { - Integration of crosscutting themes: Gender, Environment, } \\
\text { Governance }\end{array}$ \\
\hline 5.5 & - Sustainability \\
\hline & Development Effectiveness: \\
\hline 5.6 & - Partners' capacity to deliver \\
\hline 5.7 & - Strength of Partnerships \\
\hline
\end{tabular}

PWCB will assess all proposals on a comparative basis, against other proposals received within the same funding category. Please note that meeting these criteria does not automatically guarantee that a project will receive funding.

\subsection{Relevance to CIDA's Mandate and Coherence with Government of Canada Policy}

Proposals for funding must contribute to CIDA's mandate of poverty reduction. In addition, they must be consistent with the Official Development Assistance Accountability Act. The Government of Canada has the obligation to ensure that grants and contributions made to organizations do not have the effect of placing the government in the position of providing funding for projects that contravene Canadian government and foreign policy. Examples would include anti-terrorism legislation, UN or bilateral conventions, agreements and sanctions, and other Canadian domestic legislation, for example in the regulatory field.

CIDA encourages its partners to pursue opportunities by focusing their programming in the regions and sectors where they have the most experience, the best-developed networks, and where they are best aligned with local needs. CIDA will continue to support the best projects and partners from all the areas identified as priorities for the Muskoka Initiative for Matemal Newborn and Child Health. 


\subsubsection{Thematic Profile}

The Government of Canada's support for maternal and child health projects under the Muskoka Initiative Partnership Program is guided by the elements and principles of Canada's G8 2010 contribution to the Muskoka Initiative, which will focus its efforts along three key paths:

5.1.1.1 Strengthening health systems to improve health service delivery at the local level by training more health workers and expanding access for mothers and children to needed health care facilities and interventions. For example activities that improve access to antenatal care, attended childbirth, postpartum care, sexual and reproductive health care, and health education.

5.1.1.2 Improving nutrition_by increasing access to healthy and nutritious food and needed nutritional supplements that help reduce mortality. For example activities that support nutrition, education and breastfeeding, improve nutritional practices and community-level food security, and increase the provision of micronutrients.

5.1.1.3 Addressing leading diseases and illnesses that are killing mothers and children For example, activities which contribute to the prevention and treatment of HIVIAIDS, malaria, tuberculosis, diarrhoea, respiratory and infectious childhood diseases.

PWCB DOES NOT provide funding for:

- Humanitarian assistance and emergency relief

- Child sponsorship

- Internship projects or youth projects for academic credit or work camps

- Promotion of religious beliefs

- Environmental conservation activities not directly linked to poverty reduction for a particular target population (such as protection of endangered species)

- Projects that focus exclusively on construction or the provision of equipment and materials 


\subsubsection{Geographic Profile}

Projects must be implemented in eligible countries with high rates of maternal and child mortality (see box at right). PWCB will aim to concentrate half of its funding for $\mathrm{MNCH}$ in 11 of CIDA's countries of focus (listed in bold in box at right), and will concentrate $80 \%$ in Africa.

Complete the table in this section of the application form by listing the countries targeted by the proposal and the percentage of the project's total budget allocated to activities in each country. In addition, provide one or two sector codes that best represent the activities in that country.

CIDA uses sector codes developed by the OECD-DAC to code its projects and programs. The coding tables found on CIDA's website will help applicants to identify the correct coding for their project. Please code at the tertiary level (5 digits). Coding for maternal and child health projects will most often fall under the primary levels 120 (Health) and 130 (Population Policies/Programmes and Reproductive Health), however other codes may also apply.

\subsubsection{Country Specific Annexes}

For proposals involving more than one country, the main body of the proposal should cover the proposed initiative in general terms and refer to individual countries as required to promote a good understanding of the proposal. In addition, proposals should include country annexes for each country, where information on each country is summarized in a coherent way. The length of these annexes can vary depending upon the relative importance of each country in the proposal, but should average no more than two pages per country. These country annexes should be uploaded to Partners@CIDA and cover the following topics:

1. Project description and rationale

2. Objectives and expected results

3. Strategy to ensure sustainability of results locally

4. Coordination and harmonization with other development actors in the country

5. Risks and mitigation strategies

6. Overview of past activities in the country, including years of experience in the country, partners, and results achieved.

Note: Details about local partners (names, contact information, program location, role, capacity and track record of local partner(s) must be included in the Local Partners Information Form.

\subsection{Project Results and Outcomes}

\subsubsection{Relevance of Results}

The relevance of an initiative refers to its merit in terms of the needs it addresses and whom it will benefit. This section should describe why the need addressed by the proposal is important and demonstrate that it is highly valued by local beneficiaries.

$10 / 34$

PARTNERS FOR DEVELOPMENT - MUSKOKA INITIATIVE PARTNERSHIP PROGRAM 
Where applicable, proposals should:

- clearly describe the development challenges being addressed and explain how the initiative contributes to filling those needs;

- demonstrate who the initiative will benefit (directly and indirectly), whether beneficiaries are women, men, boys and/or girls, and why the initiative is of significant value to these groups (see box below);

- situate the initiative within the broader development context and show how results contribute to local development goals;

- demonstrate how the initiative builds on or fills gaps unfilled by other development actors in the country/region, including other CIDA-supported projects;

- make any relevant links to national, regional or area strategies, policies or programs and/or Millennium Development Goals (MDGs); and

- demonstrate that key stakeholders (e.g. local authorities or other levels of government) support the project and its relevance.

\subsubsection{Beneficiaries}

\section{Direct and indirect beneficiaries}

Direct beneficiaries receive something directly from a program (goods, services, training, access to resources), whereas indirect beneficiaries do not, but nonetheless benefit from successful achievement of its outcomes.

For example, a project that trains local health care workers in paediatric care and gives them access to equipment and supplies would directly benefit the health care workers (both women and men) and their households; the indirect beneficiaries might include child patients and their families.

The Canadian applicant(s) is never considered as a beneficiary, but the developing-country partner organization may be a beneficiary of the project if one or more of the project's outputs involve building the capacity of the developing-country partner.

\subsubsection{Accountability through Results-based Management}

CIDA uses three key tools in its results-based management (RBM) approach (see box on the next page) at the project-design stage: a description of project objectives and results (known as a Logic model), Performance measurement framework and a Risk register.

\subsubsection{Description of Results (Logic model-LM)}

Sometimes also called a "results chain," a LM is a depiction of the causal or logical relationships between inputs, activities, outputs, and the outcomes of a given policy, program or investment.

The LM is divided into six levels: inputs, activities, outputs, immediate outcomes, intermediate outcomes, and ultimate outcome. Each of these represents a distinct step in the causal logic of a policy, program, or investment.

The bottom three levels (inputs, activities, and outputs) address the how of an investment and they are typically the thing we can count. (e.g.:Activity: rehabilitate and staff regional health centres in region $Y$ - Outputs: regional health centres in region $Y$ rehabilitated). Make sure

PAR TNERS FOR DEVEOPLENT - MUSKOKA INIIATINE PARTNERSHP PROGRAM

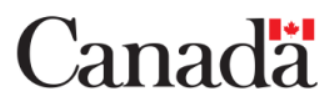


activity statements begin with a verb in the imperative form and that outputs are written as completed actions. Please note that the CIDA template does not include the input level.

The top three levels (the various outcomes) constitute the actual changes that take place: the development results. Immediate level results flow logically from the activities and outputs. They represent the change brought about by the existence of goods and/or services created through the activities, thus, the increased access to health services for people living in region $Y$. Intermediatelevel results represent a change in behaviour (e.g. increased use of health services by people living in region $Y$ ). They are the next logical step from the immediate level and lead logically to the ultimate outcome. The ultimate outcome is the highest level of change that can be achieved, a change of state for the target population. (e.g. improved health among people living in region $Y$ of country $X$ )

The Logic model must be realistic and establish clear links between activities and results. Applicants must also include gender equality, environmental sustainability, and govemance results in the Logic model (see section 5.4 on crosscutting themes). In some cases, partners may need to adjust their activities in response to changing local circumstances. Logic models should be updated to reflect these adjustments.

\subsubsection{Risk Register}

Applicants should clearly demonstrate that they have structures and controls in place to monitor risks and adjust the project plan accordingly. Applicants must submit a Risk register with the proposal and update it regularty throughout the life of the project. It should list the principal risks that may affect the achievement of expected results, the likelihood and impact that a risk may have, and a summary of the strategies to respond to those risks.

The Risk register should highlight key risks in the following areas:

- Operational risk is the potential impact of risks on the operations of the project (e.g. risks associated with human-resource allocations and management, information management, personal security, reliability of information and business operations and continuity of these even in crisis situations).

$12 / 34$

PARTNERS FOR DEVELOPAENT - MUSKOKA INIIATIVE PARTNERSFP PROGRAM

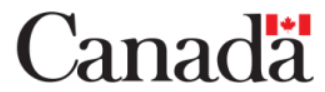


Narrative Communication Strategies

\section{References}

AMREF Canada. (2011). Who We Are. Retrieved from

http://www.amrefcanada.org/who-we-are/who-we-are/

Barthes, R. (1975). An Introduction to the Structural Analysis of Narrative. New Literary History. 6(2). 237-272.

Brown, L. \& Troutt, E. (2004). Funding Relations between Nonprofits and Government: A positive example. Nonprofit and Voluntary Sector Quarterly. 33(1). 5-27.

Canadian International Development Agency. (2010). Call for Proposals: Muskoka initiative partnership program. Retrieved from http://www.acdi-cida.gc.ca/acdicida/ACDI-CIDA.nsf/eng/ANN-111145457-Q7E\#eligibility

Canadian International Development Agency. (2011). Canada and the UN Commission on Womens and Childrens Health. Retrieved from http://www.acdi-cida.gc.ca/acdicida/ACDI-CIDA.nsf/eng/FRA-127162815-T78

Chatman, S. (1978). Story and Discourse: Narrative structure in fiction and film. Ithaca: Cornell University Press

Clarke, C. (2001). Storytelling for Grantseekers: The guide to creative nonprofit fundraising. San Francisco: Jossey-Bass, John Wiley \& Sons, Inc.

Government of Canada [Canada News Centre]. (2011). New Maternal, Newborn and Children Health Initiatives. Retrieved from http://news.gc.ca/web/article-eng.do?m=/index\&nid=585959

Johnstone, B. (2004). Discourse Analysis and Narrative. The Handbook of Discourse Analysis. Oxford: Blackwell Publishers. 
Narrative Communication Strategies

Lindloff, T. \& Taylor, B. (2002). Qualitative Communication Research Methods. Thousand Oaks: Sage Publications

Morrison, D. (1998). Aid and Ebb Tide: A history of CIDA and Canadian development assistance. Waterloo: Wilfrid Laurier University Press.

Musambira, G. (1997). Classification and Communication Network Analysis of the United States Non-Governmental Organizations (NGOs) Active in East-Africa. World Communication. 26(2). 20-44

Pratt, C. (1994). Canadian International Development Assistance Policies: An appraisal. Montreal: McGill University Press

Ramanath, R. \& Ebrahim, A. (2010). Strategies and Tactics in NGO-Government Relations: Insights from slum housing in Mumbai. Nonprofit Management \& Leadership. 21(1). 21-42.

Swift, J. \& Tomlinson, B. (1991). Conflicts of interest: Canada and the world. Toronto: Couch House Printing

World Health Organization. (2011). Millennium Development Goals (MDGs). Retrieved from http://www.who.int/topics/millennium_development_goals/en/ 